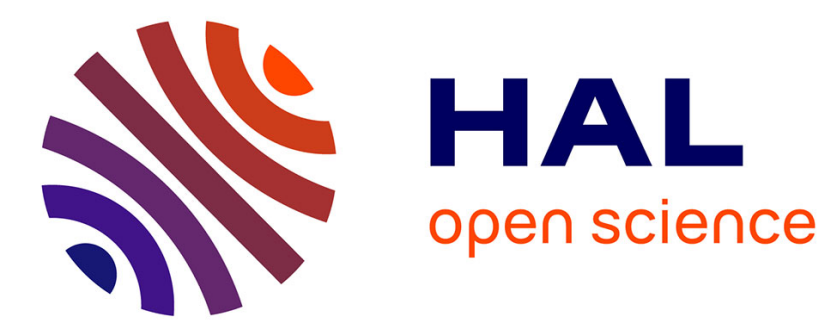

\title{
Comparative life cycle assessment of real pilot reactors for microalgae cultivation in different seasons
}

Paula Perez-Lopez, Jeroen H. de Vree, Gumersindo D Feijoo, Rouke Bosma, Maria J. Barbosa, Maria Teresa Moreira, René H. Wijffels, A.J.B van Boxtel, Dorinde Kleinegris

\section{To cite this version:}

Paula Perez-Lopez, Jeroen H. de Vree, Gumersindo D Feijoo, Rouke Bosma, Maria J. Barbosa, et al.. Comparative life cycle assessment of real pilot reactors for microalgae cultivation in different seasons. Applied Energy, 2017, 205, pp.1151-1164. 10.1016/j.apenergy.2017.08.102 . hal-01575859

\author{
HAL Id: hal-01575859 \\ https://hal.science/hal-01575859
}

Submitted on 21 Aug 2017

HAL is a multi-disciplinary open access archive for the deposit and dissemination of scientific research documents, whether they are published or not. The documents may come from teaching and research institutions in France or abroad, or from public or private research centers.
L'archive ouverte pluridisciplinaire HAL, est destinée au dépôt et à la diffusion de documents scientifiques de niveau recherche, publiés ou non, émanant des établissements d'enseignement et de recherche français ou étrangers, des laboratoires publics ou privés. 


\title{
Comparative life cycle assessment of real pilot reactors for microalgae cultivation in different seasons
}

Paula Pérez-López* ${ }^{1,2}$, Jeroen H. de Vree ${ }^{3,4}$, Gumersindo Feijoo ${ }^{1}$, Rouke Bosma ${ }^{3}$, Maria J. Barbosa $^{3}$, María Teresa Moreira ${ }^{1}$, René H. Wijffels ${ }^{3,5}$, Anton J.B. van Boxtel ${ }^{6}$, Dorinde M.M. Kleinegris ${ }^{4,7}$

${ }^{1}$ Department of Chemical Engineering, Institute of Technology, University of Santiago de Compostela. 15782 Santiago de Compostela, Spain

${ }^{2}$ MINES ParisTech, PSL Research University, Centre Observation, Impacts, Energie (O.I.E.), 1 rue Claude Daunesse, CS 10207, 06904 Sophia Antipolis Cedex, France

${ }^{3}$ Wageningen University, Bioprocess Engineering Group, AlgaePARC, P.O. Box 16, 6700 AA, Wageningen, The Netherlands

${ }^{4}$ Uni Research Environment, P.O. Box 7810, 5020 Bergen, Norway

${ }^{5}$ University of Nordland, Faculty of Biosciences and Aquaculture, N-8049, Bod $\phi$, Norway

${ }^{6}$ Wageningen University - Biobased Chemistry and Technology, P.O. Box 17, 6700 AA - Wageningen, The Netherlands

${ }^{7}$ Wageningen UR Food \& Biobased Research, AlgaePARC, P.O. Box 16, 6700 AA, Wageningen, The Netherlands

*Corresponding author: Tel.: +33 (0) 4971570 55; E-mail address: paula.perez_lopez@mines-paristech.fr

\begin{abstract}
Microalgae are promising natural resources for biofuels, chemical, food and feed products. Besides their economic potential, the environmental sustainability must be examined. Cultivation has a significant environmental impact that depends on reactor selection and operating conditions. To identify the main environmental bottlenecks for scale-up to industrial facilities this study provides a comparative life cycle assessment (LCA) of open raceway ponds and tubular photobioreactors at pilot scale. The results are based on experimental data from real pilot plants operated in summer, fall and winter at AlgaePARC (Wageningen, The Netherlands). The energy consumption for temperature regulation presented the highest environmental burden. The production of nutrients affected some categories. Despite limited differences compared to the vertical system, the horizontal PBR was found the most efficient in terms of productivity and environmental impact. The ORP was, given the Dutch climatic conditions, only feasible under summer operation. The results highlight the relevance of LCA as a tool for decision-making in
\end{abstract}


process design. Weather conditions and availability of sources for temperature regulation were identified as essential factors for the selection of geographic locations and for microalgal cultivation systems based on environmental criteria. Simulation of large-scale reactors with optimized temperature regulation systems lead to environmental improvements and energy demand reductions ranging from $17 \%$ up to $90 \%$ for systems operated in favorable summer conditions.

Keywords Microalgae cultivation, Life cycle assessment (LCA), tubular photobioreactor, open raceway pond, pilot plant, weather variations

\section{Introduction}

The scarcity of natural resources and particularly the exhaustion of fossil fuels are a global challenge to be addressed in forthcoming decades [1-3]. The current production framework based on non-renewable energies poses several problems to society, including economic instability and political conflicts (due to raw material scarcity and related increasing prices), as well as environmental concerns [4]. Alternative sources including biomass feedstocks such as vegetable oils, waste oils or algal lipids are currently under development to reduce harmful effects on environment and ecological threats such as global warming [2, 5-6].

Microalgae have shown a great potential for the production of numerous compounds with a wide variety of applications that include biofuels and other forms of energy as well as chemicals, food and feed, among others [1, 7-8]. Some advantages of microalgae compared to other bioenergy feedstocks are their higher productivity per unit, the possibility to cultivate them on marginal land in fresh- or saltwater avoiding competition with food crops and the option of coupling their growth with the treatment of waste streams [2, 5, 9-12]. Despite the advantages of microalgae and their lower requirements in categories such as land competition or eutrophication [5, 13], some aspects of environmental sustainability, such as the energy balance or greenhouse gas emissions, are still liable to improve, especially for the use of microalgae for energy applications [3, 5]. Life Cycle Assessment (LCA) has the potential to be used as a guiding tool for decision-making in process design [8, 14]. LCA may contribute to identify the main bottlenecks to be addressed during the scale up towards sustainable industrial facilities.

Algae cultivation has been identified as a major contributor to the operational and embodied energy of microalgal processes $[3,7,15]$. The total energy demand for cultivation stage usually ranges from 0.1 up to $5 \mathrm{MJ}$ energy input per $\mathrm{MJ}$ energy produced $[9,16]$. This is mainly due to 
addition of nutrients and $\mathrm{CO}_{2}[1,5]$ and the specific requirements of the selected reactor configuration, such as mixing and temperature control $[9,15,17]$.

The embodied energy for nutrients is related to manufacturing of synthetic fertilizers and the reactor materials as well as $\mathrm{CO}_{2}$ production, whereas the operational energy consumption is linked to pumping for the delivery of culture medium and $\mathrm{CO}_{2}$ [1, 5, 9]. Since algae are temperature sensitive, heating and cooling is required to operate relatively close to the optimal temperature of the algal species. Temperature regulation allows high productivities and prevents growth inhibition, but may increase the energy demand of the process [18-19]. The integration of options such as waste heat from power generation or cold water resources allows reducing the energy requirements for heating or cooling the water from room temperature to the set point temperature, and thus, contributes to the optimization of the cultivation stage [19-20]. Furthermore, climatic data including irradiation and temperature depend on geographic location. Therefore, the heating and cooling needs of the system vary between locations [21]. The selection of an appropriate location according to available resources (energy, nutrients, waste heat, cooling water) and algal strains may serve to maintain the optimal temperature with low heating and cooling requirements so that the energy consumption is minimized.

The environmental performance of cultivation is also influenced by reactor selection.
Open raceway ponds (ORPs) and closed tubular photobioreactors (PBRs) are currently considered as the two most feasible existing configurations for large-scale cultivation of microalgae $[10,15]$. Although simple reactors such as ORPs have fewer elements that consume energy than closed PBRs, the maximum biomass productivity is also lower and they are more sensitive to contamination risks. However, closed PBRs have higher costs of infrastructure and operation [15, 22]. These aspects should be considered when comparing the environmental performance of different configurations.

Numerous studies dealing with the environmental performance of different reactor designs for microalgae cultivation have been published $[1,5,9,12,15,17,20,23-24]$. However, most of this work considers hypothetical simulated scenarios or extrapolations from lab-scale data rather than existing pilot or commercial systems $[1,5,8,12,15,17,24]$. Few of them make a comparison between different reactor configurations, often restricted to a very limited set of indicators that only takes into account energy requirements and greenhouse gas emissions $[1,9,15,17]$. Moreover, they are based on average growth parameters and omit the influence of weather fluctuations, affecting reactor stability, on the environmental results.

This work provides a comparative life cycle assessment (LCA) of the two most common reactor configurations (ORPs and tubular PBRs) to evaluate the main environmental burdens of each option, to compare their performances and to 
identify bottlenecks for up-scaling. The evaluation considers the algal biomass production from the eustigmatophyte Nannochloropsis sp. due to its good biomass productivity and capability for high lipid content when stressed $[13,25]$. The evaluation is based on data from three real reactors operated in parallel at AlgaePARC pilot facility (Wageningen, The Netherlands) [26]. The use of real pilot data is expected to overcome current concerns of microalgal LCAs related to the lack of large-scale information [14]. The data are obtained for comparable weather conditions for each reactor, during three seasons (summer, fall and winter). These systems have been designed and operated as a first step to facilitate the transition from laboratory research to outdoor production for industrial applications [18].

\section{Materials and methods}

\subsection{AlgaePARC cultivation systems}

AlgaePARC is a research facility of Wageningen University and Research (The Netherlands) that was built with the aim of comparing different PBRs and optimizing process control strategies for microalgae cultivation and processing. The main objective of this facility is to develop systems with low production costs and energy requirements that can serve as a basis for the improvement of large-scale microalgae plants [18].

AlgaePARC outdoor facilities comprise several pilot-scale photobioreactors, including horizontal and vertical tubular PBRs and an ORP. Among the available systems, the operation of the
ORP, a vertical and an horizontal tubular PBR was monitored throughout the year 2013. Part of these data on photosynthetic efficiency, areal and volumetric productivities have been published in De Vree et al. [26]. The layout of each system is depicted in Figure 1. As described in Bosma et al. [18], the ORP consists of a $4.73 \mathrm{~m}^{3}$ oval pond with a separation plate in the center and two additional plates that divide each of the rounded corners into three narrower channels to improve mixing. A paddle wheel drives the culture at a controlled speed of the motor. The $\mathrm{CO}_{2}$ is dosed in a gas circulation loop, by injection at the bottom of the pond under a gas collection hood. The hood traps the $\mathrm{CO}_{2}$ enriched air, minimizing $\mathrm{CO}_{2}$ losses. Liquid culture medium is pumped from nutrient dosing stations close to the ORP and temperature is maintained above a set point with a submerged tubular heat exchanger. Active cooling was not needed.

The horizontal tubular PBR system $\left(0.56 \mathrm{~m}^{3}\right)$ consists of three loops with transparent pipes that are placed in parallel at the same height, whereas the vertical system $\left(1.06 \mathrm{~m}^{3}\right)$ is composed of seven loops with pipes "stacked" on top of each other. In both systems, the culture medium is divided over the loops by a distribution header. The accumulation of excess oxygen is avoided by using an oxygen stripper. This system receives air, blown by a compressor via a sparger at the bottom. Oxygen is transferred from the liquid to the gas phase and leaves the stripper at the top. The stripper contains three heat exchange spirals 
to keep the culture temperature between a minimum and a maximum value.

The operation of the three systems was performed under different Dutch weather conditions that can be classified as "summer", "fall" and "winter". However, the "winter" operation of the ORP was unfeasible as heavy rainfall in this period resulted in a too high dilution of the ORP in combination with the low solar radiation level and low temperatures. Geometric and average operating parameters in each reactor and season are specified in Table $\mathbf{1 .}$ a)

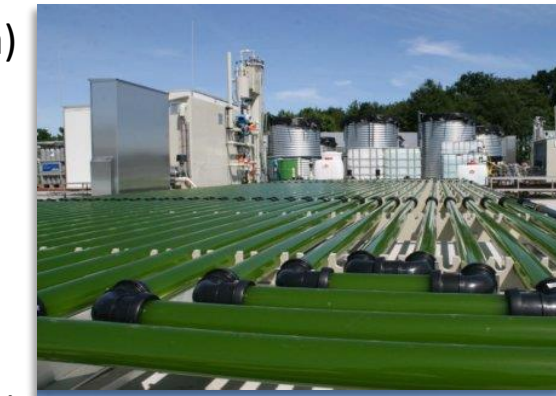

b)

c)

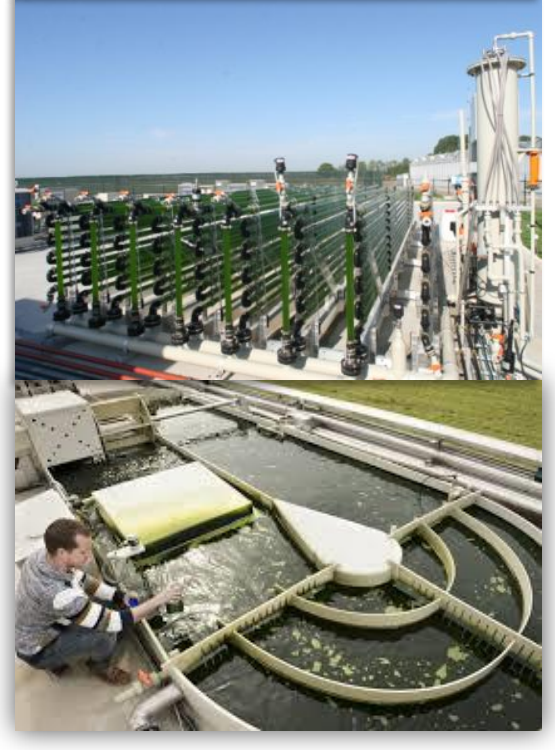

d)

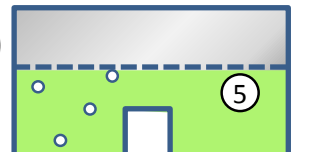

e)

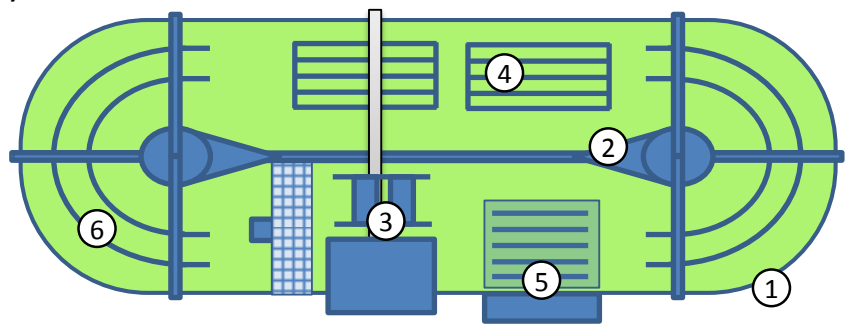

(1) Main polypropylene body

(2) Middle separation

(3) Paddlewheel and steel shaft
(1) PMMA transparent tubes

(3) Polypropylene opaque corners

(4) Aluminum support structure

(5) Oxygen stripper

(6) Internal heat exchanger
(2) Polypropylene opaque

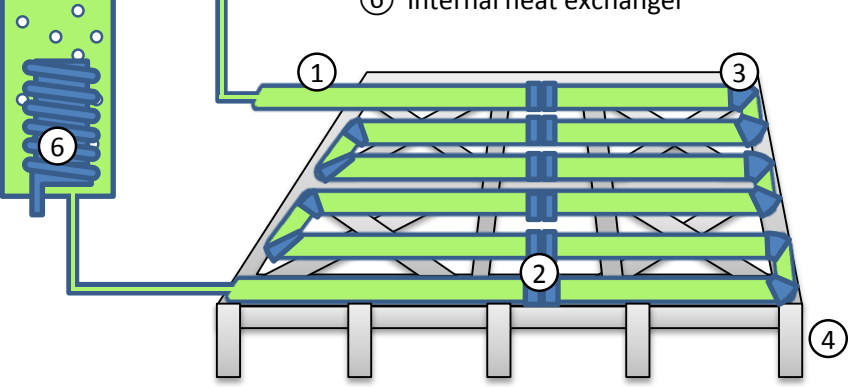

(5eat exchanger

(5) $\mathrm{CO}_{2}$ supply system

(6) Channels to improve mixing

Figure 1. Pilot-scale systems at AlgaePARC facilities: a) Horizontal tubular PBR, b) vertically stacked tubular PBR c) ORP, d) simplified scheme of the main components of the tubular reactors and e) simplified scheme of the main components of the ORP (excluding, pumps, compressors and nutrient dosage tanks). 
Table 1. Dimensions and operational average parameters for each reactor and period

\begin{tabular}{|c|c|c|c|c|c|c|c|c|}
\hline \multirow{2}{*}{$\begin{array}{l}\text { Reactor configuration } \\
\text { Season }\end{array}$} & \multicolumn{3}{|c|}{ Horizontal PBR } & \multicolumn{3}{|c|}{ Vertical PBR } & \multicolumn{2}{|c|}{ ORP } \\
\hline & Summer & Fall & Winter & Summer & Fall & Winter & Summer & Fall \\
\hline \multicolumn{9}{|l|}{ Reactor characteristics } \\
\hline Volume $\left(\mathrm{m}^{3}\right)$ & & 0.56 & & & 1.06 & & \multicolumn{2}{|c|}{4.73} \\
\hline Ground area $\left(\mathrm{m}^{2}\right)$ & & 27.0 & & & 31.0 & & \multicolumn{2}{|c|}{25.4} \\
\hline Optical path $(\mathrm{cm})$ & & 4.6 & & & 4.6 & & \multicolumn{2}{|c|}{20} \\
\hline \multicolumn{9}{|l|}{ Operational parameters } \\
\hline Start-up date & $04 / 07 / 13$ & $29 / 08 / 13$ & $04 / 11 / 13$ & $04 / 07 / 13$ & $27 / 08 / 13$ & $07 / 11 / 13$ & $08 / 07 / 13$ & $22 / 08 / 13$ \\
\hline Shutdown date & $22 / 08 / 13$ & $31 / 10 / 13$ & $16 / 12 / 13$ & $27 / 08 / 13$ & $04 / 11 / 13$ & $17 / 12 / 13$ & $22 / 08 / 13$ & $18 / 09 / 13$ \\
\hline Dilution rate $(\%)$ & 25.3 & 23.5 & 11.6 & 27.1 & 25.4 & 14.0 & 16.0 & 11.0 \\
\hline $\begin{array}{l}\text { Biomass concentration in } \\
\text { the reactor }(\mathrm{g} / \mathrm{L})\end{array}$ & 2.5 & 1.3 & 0.6 & 1.9 & 1.0 & 0.4 & 0.5 & 0.5 \\
\hline $\begin{array}{l}\text { Ground areal } \\
\text { productivity } \\
\left(\mathrm{g} \cdot \mathrm{m}^{-2} \cdot \mathrm{d}^{-1}\right)\end{array}$ & 12.1 & 4.6 & 1.2 & 19.4 & 8.3 & 2.7 & 10.5 & 2.1 \\
\hline $\begin{array}{l}\text { Volumetric productivity } \\
\left(\mathrm{g} \cdot \mathrm{m}^{-3} \cdot \mathrm{d}^{-1}\right)\end{array}$ & 654.8 & 250.2 & 66.7 & 568.5 & 241.7 & 79.2 & 56.5 & 11.3 \\
\hline $\begin{array}{l}\text { Recirculation flow } \\
\left(\mathrm{m}^{3} \cdot \mathrm{h}^{-1}\right)\end{array}$ & 8.1 & 8.1 & 8.0 & 18.7 & 18.8 & 18.7 & 0 & 0 \\
\hline Air flow $\left(\mathrm{m}^{3} \cdot \mathrm{h}^{-1}\right)$ & 5.6 & 6.0 & 6.0 & 11.6 & 10.0 & 9.7 & 0 & 0 \\
\hline $\mathrm{CO}_{2}$ flow $\left(\mathrm{L}^{-\mathrm{h}^{-1}}\right)$ & 40.1 & 21.3 & 8.8 & 53.4 & 26.1 & 14.0 & 30.3 & 30.3 \\
\hline \multicolumn{9}{|l|}{ Weather conditions } \\
\hline Temperature outside $\left({ }^{\circ} \mathrm{C}\right)$ & 21.4 & 14.4 & 5.8 & 21.4 & 14.2 & 5.8 & 21.7 & 17.5 \\
\hline $\begin{array}{l}\text { Light intensity } \\
\left(\mathrm{mol} \text { photons } \cdot \mathrm{m}^{-2} \cdot \mathrm{d}^{-1}\right)\end{array}$ & 36.9 & 18.6 & 5.0 & 36.9 & 18.6 & 4.9 & 38.2 & 23.9 \\
\hline $\begin{array}{l}\text { Photosynthetic } \\
\text { efficiency, PE (\%) }\end{array}$ & 1.5 & 1.1 & 1.0 & 2.5 & 2.1 & 2.6 & 1.1 & 0.3 \\
\hline $\begin{array}{l}\text { Mean sunlight duration } \\
\text { calculated from global } \\
\text { radiation }(\mathrm{h})^{1}\end{array}$ & 7.7 & 4.3 & 2.1 & 7.7 & 4.2 & 2.1 & 7.5 & 5.1 \\
\hline $\begin{array}{l}\text { Mean daily precipitation } \\
(\mathrm{mm})^{1}\end{array}$ & 1.2 & 4.3 & 2.9 & 1.1 & 4.5 & 2.0 & 1.3 & 3.9 \\
\hline $\begin{array}{l}\text { Mean precipitation } \\
\text { duration }(\mathrm{h})\end{array}$ & 0.6 & 2.3 & 2.2 & 0.6 & 2.4 & 1.6 & 0.7 & 2.2 \\
\hline $\begin{array}{l}\text { Mean daily cloud cover } \\
\text { (in octans) }\end{array}$ & 4.0 & 5.5 & 6.3 & 4.0 & 5.6 & 6.3 & 4.1 & 5.3 \\
\hline $\begin{array}{l}\text { Mean daily relative } \\
\text { humidity }(\%)^{1}\end{array}$ & 76 & 85 & 89 & 76 & 84 & 89 & 76 & 81 \\
\hline
\end{tabular}

${ }^{1}$ Calculated from data of the Royal Dutch Meteorological Institute (http://www.knmi.nl/index_en.html), for De Bilt weather station

\subsection{Life cycle assessment methodology}

Life Cycle Assessment (LCA) was used in the comparative evaluation of the environmental aspects and potential impacts of algae cultivation. LCA allowed a systematic evaluation of the environmental performance of the studied systems throughout the whole process chain, from raw materials extraction to microalgal cultivation and waste disposal. Following the ISO 14040 standards [27], four sequential stages were undertaken, namely i) goal and scope definition, ii) inventory analysis, iii) impact assessment and iv) interpretation of the results. The procedures 
and assumptions considered for each stage are detailed below.

\subsubsection{Goal and scope of the study}

The goal of the present study was to assess three different reactor configurations for the pilotscale production of Nannochloropsis sp in three periods of the year (summer, fall and winter). With this work, bottlenecks in environmental performance (referred to as hot spots) of the systems were identified.

Since the environmental performance of the different reactors is linked to the biomass production, the life cycle inventory and impact assessment are referred to $1 \mathrm{~kg}$ of produced biomass dry weight, contained in a $22 \%$ DW slurry, as the functional unit (FU).

The system boundaries were divided into foreground and background processes, referring to the steps that are directly affected by the study, and the processes that supply energy and materials via a homogeneous market, respectively [28]. The processes in the foreground systems were classified in four subsystems, shown in Figure 2: i) cleaning of the reactor, ii) preparation of the culture medium, iii) cultivation and iv) biomass concentration.

\section{i) Cleaning of the reactor (S1)}

In the first stage of the process, tap water was pumped to a silo $\left(6 \mathrm{~m}^{3}\right)$ and sterilized with hypochlorite $(2 \mathrm{mg} / \mathrm{L})$ and passed through activated carbon filters to remove the hypochlorite before being supplied to the systems.

Before inoculation, each reactor was flushed with sterilized tap water to ensure the absence of competing algae and protozoa. In the case of the tubular PBRs, the system was rinsed with tap water three times. In the second rinse, $3 \%$ of a disinfection agent (containing hydrogen peroxide) was added, whereas in the third one, $0.5 \mathrm{~g} / \mathrm{L}$ plastic beads for biofilm removal were used. For the ORP, tap water in a quantity equal to three times the usable volume of the reactor and a vacuum cleaning system was used for 1-2 $\mathrm{h}$ after the last washing step to remove all water.

\section{ii) Preparation of the culture medium (S2)}

The main source of nutrients for the cultivation of Nannochloropsis was natural seawater. To avoid contamination, this seawater was sterilized in an analogous manner as tap water for cleaning by adding hypochlorite $(5 \mathrm{mg} / \mathrm{L})$ and removing the chlorine with active carbon. Then, it was passed through a cascade filter $(10 \mu \mathrm{m}, 5 \mu \mathrm{m}$ and $1 \mu \mathrm{m})$ and supplied to the systems.

Additionally, culture medium with $\mathrm{NaNO}_{3}$ as the main nitrogen source was supplemented to the reactor. The nitrate solution consisted of $212 \mathrm{~g} / \mathrm{L}$ $\mathrm{NaNO}_{3}, 11.5 \mathrm{~g} / \mathrm{L} \mathrm{KH}_{2} \mathrm{PO}_{4}, 3 \mathrm{~g} / \mathrm{mL} \mathrm{Na}_{2}$ EDTA, 50 $\mathrm{mL}$ of trace mineral stock solution (see Supplementary material) and $17.5 \mathrm{~mL} \mathrm{NaOH} 4 \mathrm{M}$ to adjust $\mathrm{pH}$. For the tubular PBRs, a dosage of 10 $\mathrm{mL}$ of nitrate solution per $\mathrm{L}$ of seawater was added in the final culture medium, whereas $2 \mathrm{~mL} / \mathrm{L}$ were used in the medium of the ORP.

\section{iii) Cultivation (S3)}

This stage consisted of a semi-continuous process in which the biomass was operated with a fixed daily dilution rate and harvested according to the scheme explained by de Vree et al. [26]. As 
no source of artificial light was provided, light intensity only depended on weather conditions. To maintain temperature close to the optimal temperature of the species, a central chiller and heater were used. To minimize the energy consumption, the culture temperature varied between 20 and $30^{\circ} \mathrm{C}$. Heating was applied to prevent temperatures below $20^{\circ} \mathrm{C}$ and cooling when culture temperature rose above $30^{\circ} \mathrm{C}$. The set point was selected according to Nannochloropsis optimal range of $20-30^{\circ} \mathrm{C}$ [29]. No active cooling was needed for the ORP since cooling in this system occurs naturally by water evaporation [18]. The purity of the culture was checked microscopically (Leica Laborlux S) three times per week to minimize contamination problems.

iv) Biomass concentration (S4)

Despite similar environmental conditions, the final biomass concentration varied for a given period depending on the cultivation system and seasonally due to the different weather conditions. In order to make relevant comparisons between the performances of the different reactors, microfiltration and centrifugation were applied to obtain a defined biomass concentration (22\% DW), regardless of the reactor system and season. The life cycle inventory and determined environmental impact assessment are referred to 1 $\mathrm{kg}$ of produced biomass (dry weight), so $4.55 \mathrm{~kg}$ of slurry (22\% DW). 


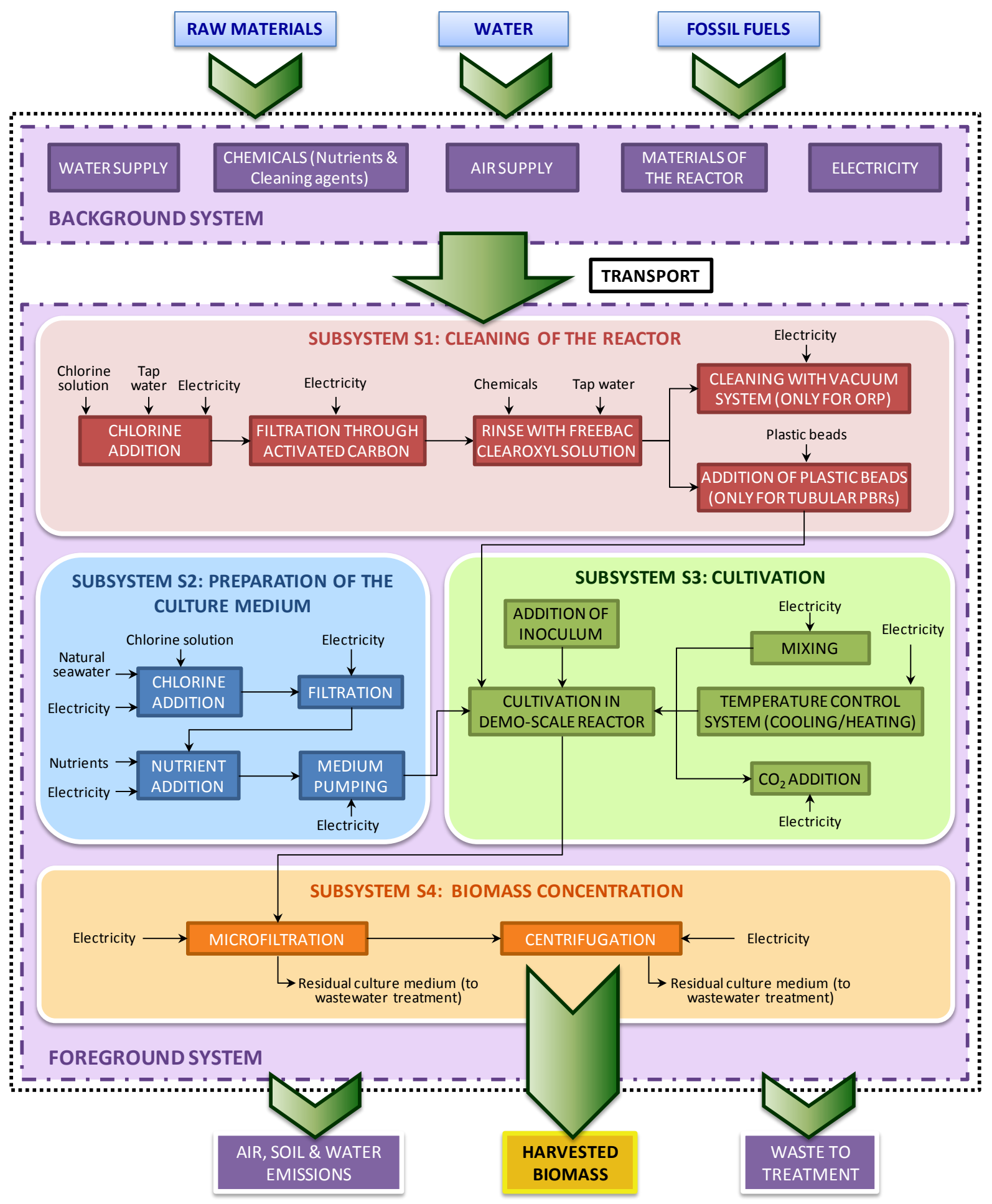

Figure 2. Process value chain and system boundaries of the cultivation of Nannochloropsis sp. in pilot-scale reactors at AlgaePARC facilities. 


\subsubsection{Inventory analysis: Data acquisition} and assumptions

The collection of inventory data related to the significant inputs and outputs to the system under study is an essential step of LCA methodology. In this study, the information for the foreground system mainly consisted of primary data collected in the facility.

The inputs and outputs for the cleaning stage (S1) were quantified with respect to the volume of water, by assuming a water consumption equal to three times the total volume of the corresponding reactor for each cleaning event. During the full monitoring period, the tubular PBRs were cleaned once after each of the six performed cultivations. For the ORP the length of each cultivation period was shorter (due to several washouts resulting from unfavorable weather conditions and high dilution rates at some periods of the operations) and 10 cleaning cycles were applied in total. The total quantity of inputs for each evaluated period was estimated according to the ratio between the duration of the period and the total feasible operation time per year (approximately 10 months).

Similarly, the water and chemicals for the preparation of the culture medium (S2) were calculated by considering the average dilution rate of each period. The energy requirements were estimated with respect to the total seawater and medium, assuming that the equipment was operating at the maximum allowed capacity.

Regarding the cultivation stage (S3), the energy consumption for the different operations (base energy of monitoring system, mixing, aeration and temperature control) was directly obtained from the on-line monitoring system. The energy consumption of the microscope for the purity check was considered negligible compared to the requirements of the reactors. The quantities of building materials for each reactor were calculated from measurements of the dimensions, which allowed determining the volume of each component and obtaining the weight by multiplying by the corresponding density. Life spans of 10 or 20 years were considered for the building materials depending on their properties and function (see Table S1 in Supplementary Material).

The inputs for the biomass concentration (S4) were the energy consumptions for the consecutive units of microfiltration and centrifuge, which were calculated according to the total volume of medium to separate from the biomass in order to achieve the final $22 \%$ DW concentration.

In all subsystems, the solid wastes were assumed to be disposed in either sanitary or inert landfills, whereas the resulting wastewater was collected in the general sewage system and treated in a conventional wastewater treatment plant. An average transport distance of $200 \mathrm{~km}$ was considered for chemicals and building materials and $50 \mathrm{~km}$ was estimated for wastes. No seawater transport was considered, since it was assumed that a commercial scale facility would be placed close to the coast. Materials for auxiliary equipment used in the process (filters, pumps, centrifuge, etc.) were neglected, since this 
equipment was shared between several systems and the corresponding quantities for each system after applying the appropriate allocation procedures would be very limited. Moreover, the equipment was common to the three analyzed reactors and thus, no additional information for the comparative purposes of the present work would be obtained.

The inventory data related to the background system were obtained from Ecoinvent database [30]. These inputs include the production of the chemicals required for the cleaning and the nutrients for the culture medium, as well as the production of electricity used throughout the stages of the processes, the manufacture of the building materials for each reactor and the waste disposal. With regard to $\mathrm{NaNO}_{3}$ production, this process is not defined in the Ecoinvent database. Therefore, the considered inventory data correspond to the synthetic process as described by Pérez-López et al. [7].

No allocation procedure was required, according to the goal of the study (the comparison of the different reactor configurations). Thus, all the environmental burdens were allocated to the total quantity of biomass harvested from each reactor.

The inventory data of the assessed scenarios are shown in Table 2.

Table 2. Inventory table for the cultivation of microalgae Nannochloropsis in pilot-scale systems (FU: $1 \mathrm{~kg}$ DW harvested biomass in $22 \%$ DW slurry).

\begin{tabular}{|c|c|c|c|c|c|c|c|c|}
\hline \multirow{2}{*}{$\begin{array}{l}\text { Reactor configuration } \\
\text { Season }\end{array}$} & \multicolumn{3}{|c|}{ Horizontal PBR } & \multicolumn{3}{|c|}{ Vertical PBR } & \multicolumn{2}{|c|}{ ORP } \\
\hline & Summer & Fall & Winter & Summer & Fall & Winter & Summer & Fall \\
\hline \multicolumn{9}{|c|}{ INPUTS from TECHNOSPHERE } \\
\hline \multicolumn{9}{|l|}{ Materials } \\
\hline \multicolumn{9}{|l|}{ S1. Cleaning } \\
\hline Tap water $(\mathrm{L})$ & 128 & 398 & 994 & 163 & 439 & 977 & 2959 & 15984 \\
\hline Chlorine solution $(\mathrm{g})$ & 4.49 & 13.9 & 34.8 & 5.70 & 15.4 & 34.2 & 104 & 559 \\
\hline Disinfectant $(\mathrm{kg})$ & 1.56 & 4.84 & 12.1 & 1.98 & 5.34 & 11.9 & 0 & 0 \\
\hline Plastic beads $(\mathrm{g})$ & 21.4 & 66.3 & 166 & 27.1 & 73.2 & 163 & 0 & 0 \\
\hline \multicolumn{9}{|l|}{ S2. Nutrient supply } \\
\hline Chlorine solution (g) & 17.8 & 43.3 & 88.6 & 21.9 & 47.9 & 90.1 & 145 & 649 \\
\hline Deionized water $(\mathrm{kg})$ & 3.85 & 9.33 & 19.1 & 4.71 & 10.3 & 19.4 & 6.27 & 28.0 \\
\hline $\mathrm{FeSO}_{4} \cdot 7 \mathrm{H}_{2} \mathrm{O}(\mathrm{g})$ & 6.45 & 15.7 & 32.1 & 7.90 & 17.3 & 32.6 & 10.5 & 47.0 \\
\hline $\mathrm{MnCl}_{2} \cdot 2 \mathrm{H}_{2} \mathrm{O}(\mathrm{g})$ & 0.368 & 0.893 & 1.83 & 0.451 & 0.988 & 1.86 & 0.600 & 2.68 \\
\hline $\mathrm{ZnSO}_{4} \cdot 7 \mathrm{H}_{2} \mathrm{O}(\mathrm{g})$ & 0.142 & 0.344 & 0.705 & 0.174 & 0.381 & 0.717 & 0.231 & 1.03 \\
\hline $\mathrm{Co}\left(\mathrm{NO}_{3}\right)_{2} \cdot 6 \mathrm{H}_{2} \mathrm{O}(\mathrm{g})$ & 0.0151 & 0.0365 & 0.0748 & 0.0184 & 0.0405 & 0.0760 & 0.0245 & 0.110 \\
\hline $\mathrm{CuSO}_{4} \cdot 5 \mathrm{H}_{2} \mathrm{O}(\mathrm{g})$ & 0.0051 & 0.0125 & 0.0256 & 0.0063 & 0.0139 & 0.0261 & 0.0084 & 0.0376 \\
\hline $\mathrm{Na}_{2} \mathrm{MoO}_{4} \cdot 2 \mathrm{H}_{2} \mathrm{O}(\mathrm{g})$ & 0.0521 & 0.126 & 0.259 & 0.0638 & 0.140 & 0.263 & 0.0849 & 0.379 \\
\hline $\mathrm{Na}_{2}$ EDTA $2 \mathrm{H}_{2} \mathrm{O}(\mathrm{g})$ & 22.6 & 54.8 & 112 & 27.7 & 60.7 & 114 & 36.8 & 164 \\
\hline $\mathrm{NaNO}_{3}(\mathrm{~kg})$ & 0.912 & 2.21 & 4.53 & 1.12 & 2.45 & 4.61 & 1.49 & 6.64 \\
\hline $\mathrm{KH}_{2} \mathrm{PO}_{4}(\mathrm{~g})$ & 49.5 & 120 & 246 & 60.6 & 133 & 250 & 80.7 & 360 \\
\hline $\mathrm{NaOH}(\mathrm{g})$ & 13.8 & 33.4 & 68.4 & 16.9 & 37.0 & 69.5 & 22.4 & 100 \\
\hline \multicolumn{9}{|l|}{ S3. Cultivation } \\
\hline Biomass (g) & 84.1 & 197 & 210 & 100 & 189 & 206 & 399 & 3045 \\
\hline
\end{tabular}




\begin{tabular}{|c|c|c|c|c|c|c|c|c|}
\hline \multirow{3}{*}{$\begin{array}{l}\text { PMMA (kg) } \\
P P(k g)\end{array}$} & & & & & \\
\hline & 0.122 & 0.380 & 0.951 & 0.301 & 0.813 & 1.81 & 0.012 & 0.066 \\
\hline & 0.077 & 0.239 & 0.598 & 0.068 & 0.182 & 0.406 & 1.49 & 8.02 \\
\hline Steel $(\mathrm{kg})$ & 0 & 0 & 0 & 0.015 & 0.040 & 0.089 & 0.136 & 0.737 \\
\hline Aluminum $(\mathrm{kg})$ & 0.192 & 0.594 & 1.49 & 0.136 & 0.368 & 0.819 & 0 & 0 \\
\hline Synthetic rubber $(\mathrm{g})$ & 0 & 0 & 0 & 8.78 & 23.7 & 52.7 & 4.32 & 23.3 \\
\hline Compressed air $\left(\mathrm{m}^{3}\right)$ & 479 & 1363 & 4653 & 503 & 1125 & 2940 & 0 & 0 \\
\hline Carbon dioxide $\left(\mathrm{m}^{3}\right)$ & 3.44 & 4.83 & 6.82 & 2.31 & 2.94 & 4.25 & 3.43 & 22.7 \\
\hline \multicolumn{9}{|l|}{ Energy } \\
\hline \multicolumn{9}{|l|}{ S1. Cleaning } \\
\hline Filtration $(\mathrm{kWh})$ & 0.026 & 0.082 & 0.204 & 0.033 & 0.090 & 0.201 & 0.608 & 3.29 \\
\hline Vacuum system (kWh) & 0 & 0 & 0 & 0 & 0 & 0 & 1.72 & 9.29 \\
\hline \multicolumn{9}{|l|}{ S2. Nutrient supply } \\
\hline Water pumping (kWh) & 0.118 & 0.287 & 0.588 & 0.145 & 0.318 & 0.597 & 0.964 & 4.31 \\
\hline Filtration $(\mathrm{kWh})$ & 0.140 & 0.340 & 0.697 & 0.172 & 0.377 & 0.708 & 1.14 & 5.10 \\
\hline Mixing (kWh) & 0.029 & 0.070 & 0.143 & 0.035 & 0.077 & 0.145 & 0.047 & 0.209 \\
\hline \multicolumn{9}{|l|}{ S3. Cultivation } \\
\hline Base energy (kWh) & 14.6 & 38.6 & 132 & 8.22 & 21.5 & 57.8 & 5.67 & 37.5 \\
\hline Aeration and $\mathrm{CO}_{2}(\mathrm{kWh})$ & 51.5 & 136 & 466 & 20.3 & 53.1 & 143 & 26.1 & 173 \\
\hline Mixing (kWh) & 21.7 & 60.4 & 139 & 33.3 & 89.4 & 120 & 89.5 & 619 \\
\hline Heating (kWh) & 35.3 & 286 & 2496 & 61.0 & 549 & 3267 & 198 & 4873 \\
\hline Cooling (kWh) & 157 & 46.7 & 0 & 152 & 34.5 & 0 & 0 & 0 \\
\hline \multicolumn{9}{|l|}{ S4. Biomass concentration } \\
\hline Microfiltration $(\mathrm{kWh})$ & 0.176 & 0.428 & 0.875 & 0.216 & 0.473 & 0.890 & 1.44 & 6.42 \\
\hline Centrifugation (kWh) & 0.199 & 0.484 & 0.991 & 0.244 & 0.536 & 1.01 & 1.63 & 7.26 \\
\hline \multicolumn{9}{|l|}{ Transport } \\
\hline \multicolumn{9}{|l|}{ S1. Cleaning } \\
\hline Chemicals $(\mathrm{kg} \cdot \mathrm{km})$ & 313 & 970 & 2425 & 397 & 1072 & 2384 & 20.7 & 112 \\
\hline Materials $(\mathrm{kg} \cdot \mathrm{km})$ & 4.28 & 13.3 & 33.1 & 5.43 & 14.6 & 32.6 & 0 & 0 \\
\hline Wastes $(\mathrm{kg} \cdot \mathrm{km})$ & 1.07 & 3.31 & 8.28 & 1.36 & 3.66 & 8.14 & 0 & 0 \\
\hline \multicolumn{9}{|l|}{ S2. Nutrient supply } \\
\hline Chemicals $(\mathrm{kg} \cdot \mathrm{km})$ & 205 & 496 & 1016 & 251 & 450 & 1033 & 357 & 1593 \\
\hline \multicolumn{9}{|l|}{ S3. Cultivation } \\
\hline Materials $(\mathrm{kg} \cdot \mathrm{km})$ & 78.3 & 243 & 607 & 106 & 286 & 635 & 328 & 1770 \\
\hline Wastes $(\mathrm{kg} \cdot \mathrm{km})$ & 19.6 & 60.7 & 152 & 26.5 & 71.4 & 159 & 81.9 & 442 \\
\hline \multicolumn{9}{|c|}{ INPUTS from ENVIRONMENT } \\
\hline \multicolumn{9}{|l|}{ S2. Nutrient supply } \\
\hline Seawater $(\mathrm{L})$ & 426 & 1033 & 2116 & 522 & 1144 & 2151 & 3500 & 15628 \\
\hline \multicolumn{9}{|l|}{ S3. Cultivation } \\
\hline Occupation, land $\left(\mathrm{m}^{2}\right.$ year $)$ & 0.385 & 1.19 & 2.98 & 0.265 & 0.714 & 1.59 & 0.592 & 2.86 \\
\hline \multicolumn{9}{|c|}{$\begin{array}{l}\text { OUTPUTS to TECHNOSPHERE } \\
\end{array}$} \\
\hline \multicolumn{9}{|l|}{ Product } \\
\hline Microalgal biomass (kg) & & 1 & & & 1 & & & \\
\hline Wastes & & & & & & & & \\
\hline S1. Cleaning & & & & & & & & \\
\hline Plastic beads to landfill (g) & 21.4 & 66.3 & 166 & 27.1 & 73.2 & 163 & 0 & 0 \\
\hline $\begin{array}{l}\text { Wastewater to treatment } \\
\text { plant (L) }\end{array}$ & 130 & 402 & 1004 & 165 & 444 & 987 & 2959 & 15984 \\
\hline S3. Cultivation & & & & & & & & \\
\hline PMMA (kg) & 0.122 & 0.380 & 0.951 & 0.302 & 0.813 & 1.81 & 0.012 & 0.066 \\
\hline $\mathrm{PP}(\mathrm{kg})$ & 0.077 & 0.239 & 0.598 & 0.068 & 0.182 & 0.406 & 1.49 & 8.02 \\
\hline Steel $(\mathrm{kg})$ & 0 & 0 & 0 & 0.015 & 0.040 & 0.089 & 0.136 & 0.737 \\
\hline Aluminum (kg) & 0.192 & 0.594 & 1.49 & 0.136 & 0.368 & 0.819 & 0 & 0 \\
\hline Synthetic rubber $(\mathrm{g})$ & 0 & 0 & 0 & 8.78 & 23.7 & 52.7 & 4.32 & 23.3 \\
\hline
\end{tabular}




$522 \quad 1150 \quad 2166$

\subsubsection{Life cycle impact assessment}

The environmental profile of the described systems was assessed by performing the classification and characterization stages of the LCA methodology [27]. Normalization and weighting were not conducted as these optional elements were not considered to provide relevant information for the objectives of the study. Two methodologies were used: CML 2001, reported by the Centre of Environmental Science of Leiden University [31] and the Cumulative Energy Demand (CED) based on the method published by Ecoinvent version 2.0 and expanded by PRé Consultants [32].

The impact categories were selected according to the most relevant environmental issues related to microalgal products and used in previous LCA studies [7, 23, 33-34]. Eleven potential impact categories (specified in Table 3) were evaluated according to the CML 2001 methodology. CED methodology was applied to obtain the total energy consumption throughout the whole process (Total CED), which included three categories of non-renewable sources of energy and three categories of renewable sources. The inventory data were implemented in the software SimaPro 8 [35].

\section{Results and discussion}

3.1. Identification of hot spots for each reactor configuration
The LCA characterization results for the two applied methodologies (CML and CED) in each of the eight evaluated scenarios are listed in Table 3.

Figure 3a shows the average distribution of impacts for each reactor configuration, for the subsystems cleaning (S1), nutrient supply (S2), cultivation (S3) and concentration (S4). Figure 3 shows that, as expected, the cultivation stage is the main hot spot for all the reactors in nearly all the analyzed categories, with $80 \%$ or more impact. This result confirms, for all operational systems, the findings of previous studies based on hypothetical scenarios with extrapolated data regarding the importance of cultivation stage $[3,9$, 15]. These studies indicated that energy requirements and GWP of algal cultivation could represent more than $90 \%$ of the total environmental burdens for tubular PBRs and 55\% for the ORP $[9,15]$. For AlgaePARC facility, the main contributions to the total CED are those of NR-F (85\% of total CED) and NR-N (10\% total CED). These are two important categories that can be reduced by minimizing the energy requirements for algal products.

Concerning S2, only the CML categories of AP, EP, TEP and POFP, as well as the CED category of NR-B show significant contributions. Most of these contributions are associated to the production of the nitrogen source. S1 and S4 have a very limited contribution to all the evaluated categories. S4 has for all categories more 
influence for the ORP than for the tubular PBRs.

This is because the achieved biomass concentrations in the ORP are significantly lower than in the tubular PBRs. Both S1 and S4 have contributions above 5\% for the categories of EP, TEP and R-HYD. For the tubular PBRs, the highest contribution from $\mathrm{S} 1$ is associated with the category of HTP, with only $4-6 \%$, while the contribution from S4 only exceeds $1 \%$ for the summer and fall periods in the categories of EP, TEP and R-HYD.

Table 3. Characterization results for the cultivation of microalgae Nannochloropsis in real pilot-scale systems (FU: 1 kg DW harvested biomass in $22 \%$ DW slurry).

\begin{tabular}{|c|c|c|c|c|c|c|c|c|c|}
\hline \multirow{2}{*}{\multicolumn{2}{|c|}{ Impact category }} & \multicolumn{3}{|c|}{ Horizontal PBR } & \multicolumn{3}{|c|}{ Vertical PBR } & \multicolumn{2}{|c|}{ ORP } \\
\hline & & Summer & Fall & Winter & Summer & Fall & Winter & Summer & Fall \\
\hline \multirow{11}{*}{ 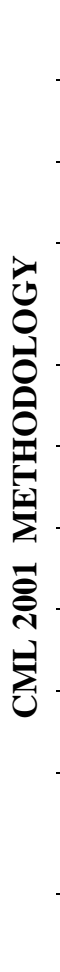 } & $\begin{array}{l}\text { Abiotic depletion, ADP } \\
\text { (kg Sb eq) }\end{array}$ & 1.66 & 3.40 & 18.6 & 1.64 & 4.43 & 20.6 & 1.98 & 33.0 \\
\hline & $\begin{array}{l}\text { Acidification, } \mathrm{AP}\left(\mathrm{kg} \mathrm{SO}_{2}\right. \\
\text { eq) }\end{array}$ & 0.460 & 0.996 & 4.36 & 0.485 & 1.23 & 4.77 & 0.605 & 7.51 \\
\hline & $\begin{array}{l}\text { Eutrophication, EP (kg } \\
\left.\mathrm{PO}_{4}{ }^{3-} \mathrm{eq}\right)\end{array}$ & 0.361 & 0.753 & 3.87 & 0.363 & 0.96 & 4.26 & 0.514 & 7.15 \\
\hline & $\begin{array}{l}\text { Global Warming } \\
\text { Potential, GWP }\left(\mathrm{kg} \mathrm{CO}_{2}\right. \\
\text { eq) }\end{array}$ & 216 & 443 & 2409 & 214 & 574 & 2665 & 256 & 4256 \\
\hline & $\begin{array}{l}\text { Ozone layer depletion, } \\
\text { ODP (kg CFC-11 eq) }\end{array}$ & $7.68 \cdot 10^{-6}$ & $1.58 \cdot 10^{-5}$ & $8.34 \cdot 10^{-5}$ & $7.56 \cdot 10^{-6}$ & $2.01 \cdot 10^{-5}$ & $9.17 \cdot 10^{-5}$ & $9.19 \cdot 10^{-6}$ & $1.47 \cdot 10^{-4}$ \\
\hline & $\begin{array}{l}\text { Human Toxicity, HTP (kg } \\
\text { 1,4-DB eq) }\end{array}$ & 52.5 & 115 & 525 & 49.7 & 130 & 546 & 55.2 & 836 \\
\hline & $\begin{array}{l}\text { Freshwater Ecotoxicity, } \\
\text { FEP(kg 1,4-DB eq) }\end{array}$ & 50.8 & 105 & 565 & 49.9 & 134 & 621 & 66.8 & 1027 \\
\hline & $\begin{array}{l}\text { Marine Ecotoxicity, } \\
\text { MEP(kg 1,4-DB eq) }\end{array}$ & 33.0 & 68.2 & 366 & 32.4 & 87.1 & 403 & 42.4 & 661 \\
\hline & $\begin{array}{l}\text { Terrestrial Ecotoxicity, } \\
\text { TEP(kg 1,4-DB eq) }\end{array}$ & 0.007 & 0.014 & 0.073 & 0.007 & 0.018 & 0.081 & 0.009 & 0.134 \\
\hline & $\begin{array}{l}\text { Photochemical oxidants' } \\
\text { formation, POFP (kg } \\
\left.\mathrm{C}_{2} \mathrm{H}_{4} \mathrm{eq}\right)\end{array}$ & 0.016 & 0.035 & 0.169 & 0.016 & 0.043 & 0.185 & 0.020 & 0.295 \\
\hline & $\begin{array}{l}\text { Land competition, } \mathrm{LC} \\
\left(\mathrm{m}^{2} \text { year }\right)\end{array}$ & 4.32 & 9.23 & 46.90 & 4.13 & 11.1 & 50.1 & 5.29 & 81.2 \\
\hline \multirow{3}{*}{ 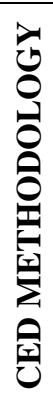 } & $\begin{array}{l}\text { Non-renewable fossil } \\
\text { energy demand, NR-F } \\
\text { (MJ) }\end{array}$ & 3010 & 6179 & 33692 & 2983 & 8033 & 37315 & 3610 & 59727 \\
\hline & $\begin{array}{l}\text { Non-renewable nuclear } \\
\text { energy demand, NR-N } \\
\text { (MJ) }\end{array}$ & 377 & 771 & 4187 & 370 & 994 & 4622 & 455 & 7449 \\
\hline & $\begin{array}{l}\text { Non-renewable energy } \\
\text { demand from biomass of } \\
\text { primary forests, NR-B } \\
\text { (MJ) }\end{array}$ & $2.76 \cdot 10^{-3}$ & $6.38 \cdot 10^{-3}$ & $1.99 \cdot 10^{-2}$ & $3.10 \cdot 10^{-3}$ & $7.30 \cdot 10^{-3}$ & $2.09 \cdot 10^{-2}$ & $3.89 \cdot 10^{-3}$ & $3.13 \cdot 10^{-2}$ \\
\hline
\end{tabular}


Renewable energy

demand from food and

agricultural sources, R-B

(MJ)

Renewable energy

demand from solar, wind

and geothermal, R-WSG

(MJ)

Renewable energy

demand from

hydropower, R-HYD

(MJ)

TOTAL CUMULATIVE

ENERGY DEMAND,

CED (MJ)

\begin{tabular}{|c|c|c|c|c|c|c|c|}
\hline 105 & 215 & 1213 & 104 & 282 & 1345 & 125 & 2156 \\
\hline 27.4 & 55.6 & 314 & 26.9 & 72.9 & 348 & 32.1 & 557 \\
\hline 18.7 & 42.7 & 180 & 17.3 & 45.2 & 180 & 20.1 & 275 \\
\hline 3539 & 7263 & 39587 & 3501 & 9427 & 43811 & 4242 & 70164 \\
\hline
\end{tabular}




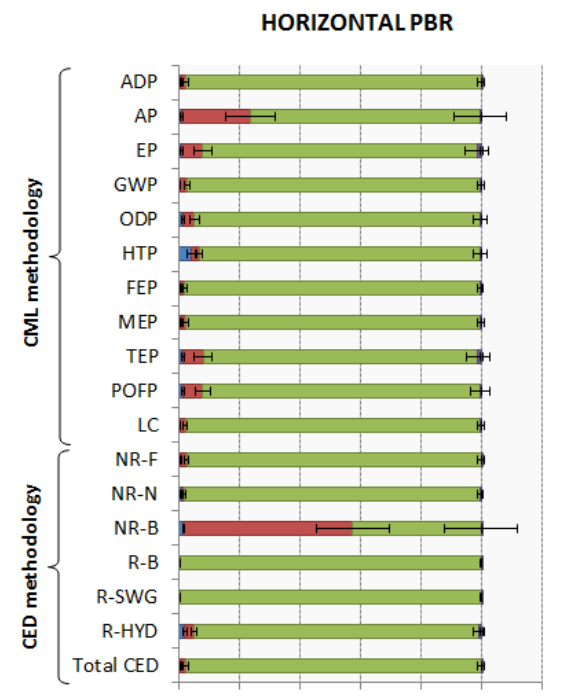

$\begin{array}{lllllll}0 \% & 20 \% & 40 \% & 60 \% & 80 \% & 100 \% & 120 \%\end{array}$

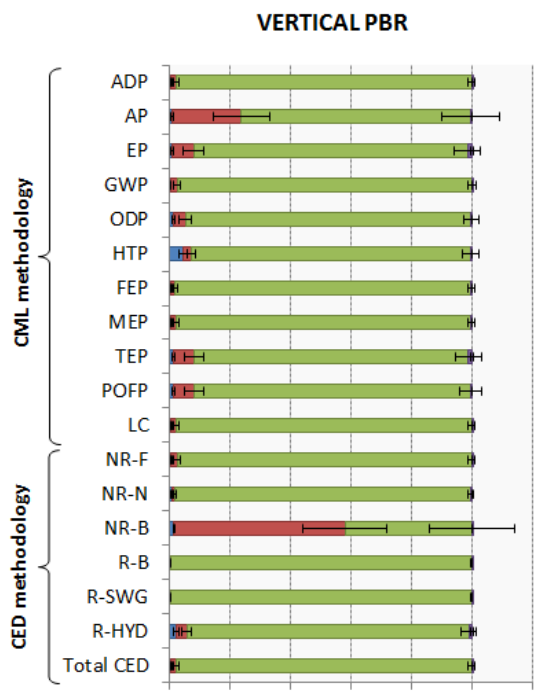

$\begin{array}{llllllll}0 \% & 20 \% & 40 \% & 60 \% & 80 \% & 100 \% & 120 \%\end{array}$

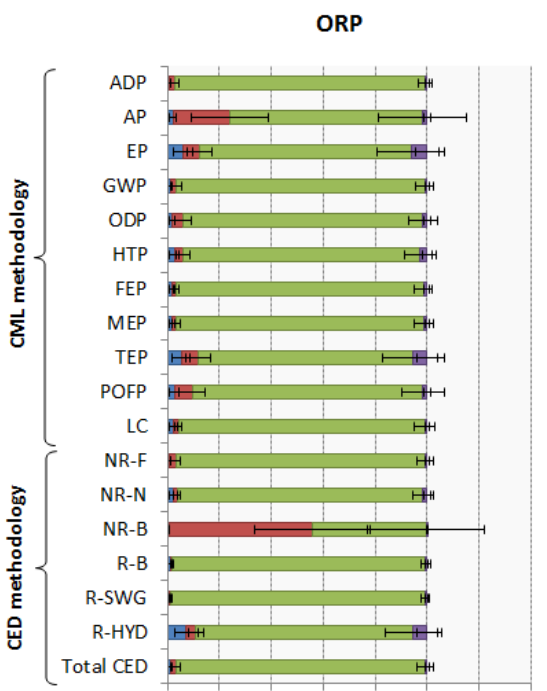

$\begin{array}{lllll}0 & 20 \% & 40 \% \quad 60 \% \quad 80 \% & 100 \% 120 \% 140 \%\end{array}$

\$ 1 . Cleaning stage

¿S2. Nutrient supply

$\square$ S3. Cultivation

\4. Biomass concentration

b) Hot spots per production process

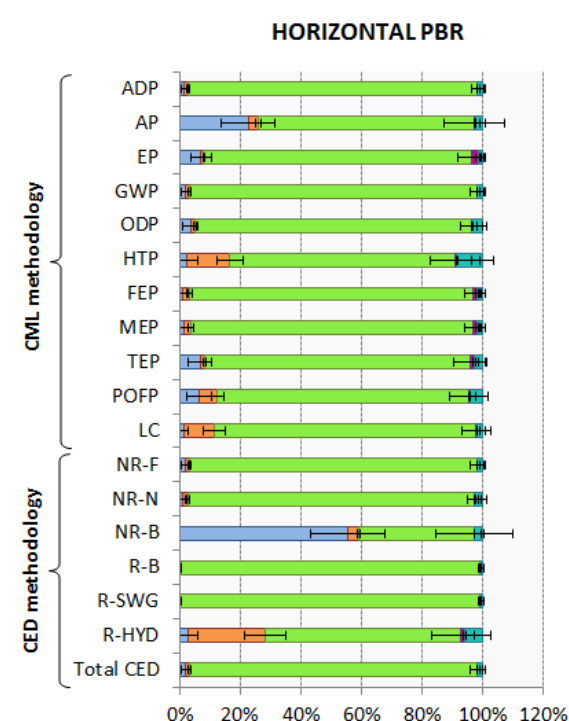

$\begin{array}{llllllll}0 \% & 20 \% & 40 \% & 60 \% & 80 \% & 100 \% & 120 \%\end{array}$

$\square$ Nutrients $\quad \square$ Infrastructure

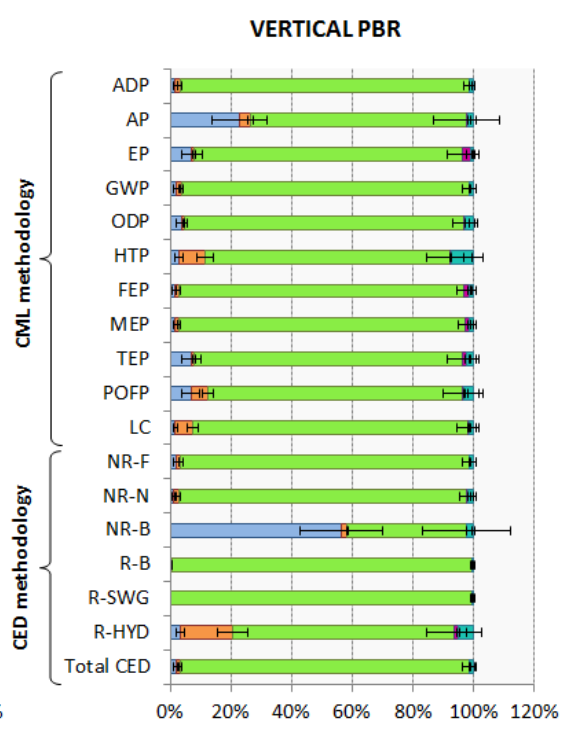

$\square$ Electricity for cultivation

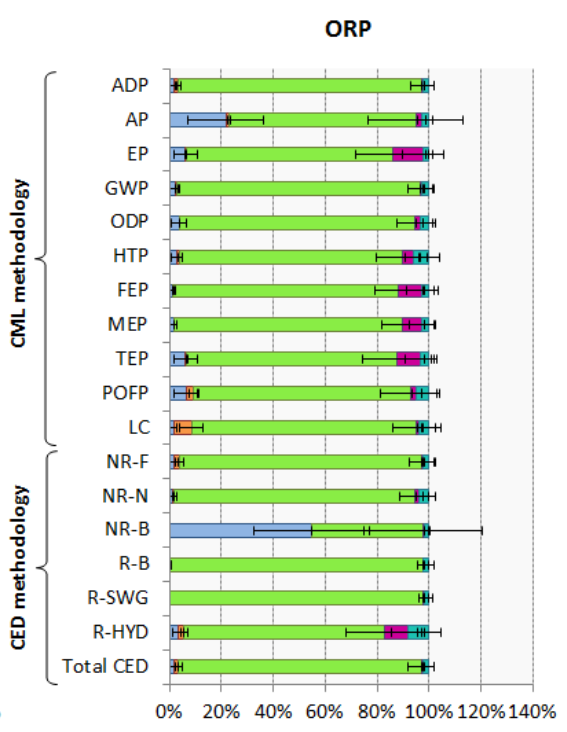

Waste treatment

$\square$ Others

Figure 3. Relative contributions to the environmental burdens of a) the subsystems and b) the production processes involved in the operation of the compared pilot-reactor configurations. For each category, $100 \%$ corresponds to the environmental impacts for each reactor (considering the average of the three operation periods) indicated in Table 2.

Figure 3b illustrates the breakdown of the contributions per involved production process. The impact of the electricity production for cultivation constitutes the main environmental burden of S3. The figure shows that electricity for cultivation has contributions between $80-95 \%$ in 
most of the categories. The role of energy requirements with respect to the total environmental impacts is consistent with other studies in which the electricity for cultivation has been identified as the main hot spot, but with slightly lower relative contributions than that of AlgaePARC pilot systems [14-15, 20, 33]. For example, Stephenson et al. [15] reported that electrical power during cultivation in ORPs has a contribution of $74 \%$ to fossil energy requirement and $65 \%$ to GWP. Similarly, energy was identified by Lardon et al. [34] as one of the main causes of impact for a raceway pond (with contributions between $42-75 \%$ to CED and $18-36 \%$ to GWP), together with fuel combustion and use of fertilizers.

As further discussed in section 3.2., the main reason for the high energy consumption is the use of an electrical heater and chiller in this pilot plant. These units, used for temperature control, work fine for a pilot facility, but at large scale should be replace by much more efficient technologies, for example, using waste heat or a storage temperature buffer in the ground. It should be remarked that the absolute values in Table 3 are based on pilot-scale systems, and may change significantly after scaling up to commercial scale. Electrical efficiencies of the equipment are expected to improve in commercial systems [36]. This improvement jointly with optimized equipment dimensioning (to avoid oversizing) could reduce the energy consumption by approximately $66 \%$ when moving from pilot to full scale [37]. The main trends for up-scaling, including the expected differences between the evaluated pilot-scale systems and hypothetical industrial-scale facilities, are presented in section 3.4 .

The production of building materials for the reactors (plastics, steel and aluminum grouped as "infrastructure" in Figure 3b) or the compressed carbon dioxide, also included in S3, have low contributions. The infrastructure is responsible for more than $5 \%$ of the impacts in six of the eight assessed scenarios: HTP, POFP, LC and R-HYD. The contribution of this production process only exceeds $16 \%$ for the category of R-HYD. However, this category represented less than $1 \%$ of total CED in all scenarios. Most of the impacts from infrastructure are associated with the production of metals, specifically aluminum for the tubular PBRs (used for the supporting structure) and steel for the ORP (among others used for the shaft of the paddle wheel and the tubes of the heat exchanger).

Among the other processes, the production of nutrients has the highest impact, although it is restricted to the categories AP (between 14-30\% depending on the season), NR-B (from $40 \%$ to $65 \%$ ) and to a lesser extent to EP, TEP and POFP (from 4 to $10 \%$ ). Sodium nitrate, which comprises more than $90 \%$ of the nutrients, has the highest contribution. Substituting the main nitrogen source by other alternatives would have a limited effect on impact reduction under the evaluated conditions. This finding differs with previous research that mentions a noticeable influence of the production of fertilizers in the environmental 
profile $[1,5,34]$. The low relative contribution of nutrients is caused by the higher contribution of electricity of the pilot-scale reactors, which attenuates the relative contribution of the other processes. In addition, the use of assumptions and extrapolated laboratory data for productivity used in life cycle and techno-economic studies of algal biofuels may lead to underestimation of the required raw materials due to the overestimation of the productivity potential [21].

The relative contribution of nutrient production in the environmental profile depends on the season of cultivation. Summer period presented higher productivities (linked to higher dilution rates) and lower electricity requirements than fall and winter operation due to high temperatures and light intensities. Higher dilution rates require large quantities of nutrients to replace the harvested culture volume. Electricity consumption is lower in summer due to low heating requirements compared to fall and winter, which largely compensate energy needs for cooling. The combined effect of higher dilution rates and lower electricity requirements lead to a higher relative contribution of nutrients to the environmental burdens in summer than in fall and winter.

Waste treatment has a moderate contribution (around 10\%) for ORP scenarios to EP and toxicity categories (FEP, MEP, TEP) and to RHYD, while its influence is below $3 \%$ for the tubular PBRs in all categories and conditions. This impact was linked to the treatment of wastewater from S1 and S4. The difference is mainly due to the larger volume of water required by the ORP both for biomass production and cleaning, per functional unit. Although the tubular PBRs required the addition of chemicals (disinfectant) and materials (plastic beads) with higher impacts, they needed a lower number of cleanings and produced more biomass per year than ORP, according to the operation during the reference year. A minor difference in waste treatment between the ORP and tubular reactor results from S4. The harvested biomass from the ORP has a lower concentration than the biomass from the tubular PBRs, and therefore a higher volume of wastewater was generated to achieve the same biomass concentration.

\subsection{Distribution of electricity requirements during} the cultivation stage (S3)

The identification of the hot spots reveals that production of electricity for the cultivation of Nannochloropsis sp. is the major contributor to the environmental impact for all the reactor designs and operating conditions. These energy requirements arise from four activities: 1) temperature regulation (including heating and cooling of the culture medium), 2) aeration, 3) mixing and 4) base energy of monitoring system. To determine the relevance of each activity, the distribution of electricity consumption is depicted in Figure 4. 
Horizontal PBR - Summer

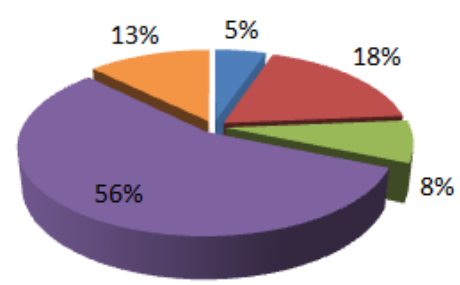

Vertical PBR - Summer

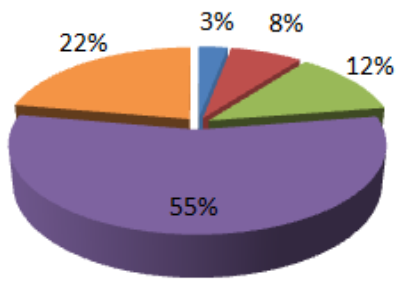

ORP - Summer

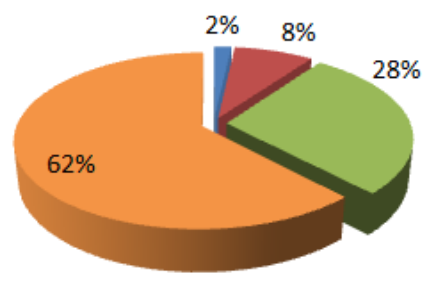

Horizontal PBR - Fall

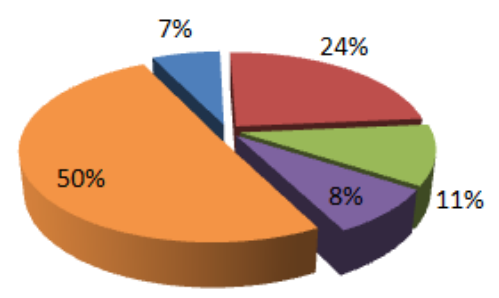

Vertical PBR - Fall

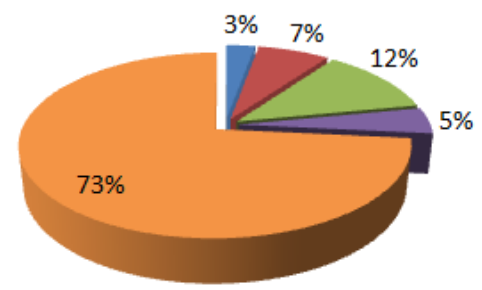

ORP - Fall

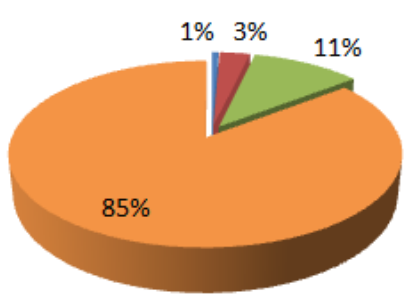

Horizontal PBR - Winter

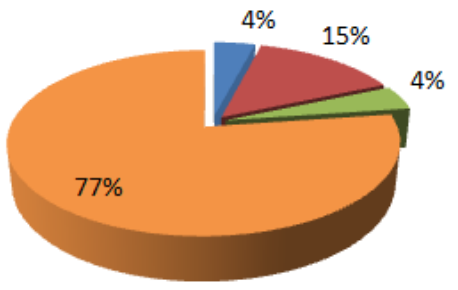

Vertical PBR - Winter

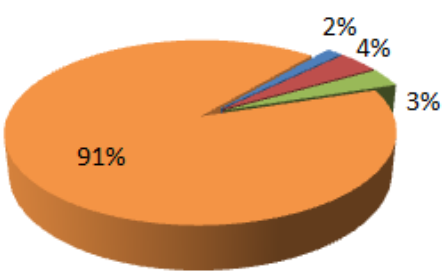

n Base energy

- Aeration and $\mathrm{CO}_{2}$ addition

m Mixing

- Cooling

- Heating

Figure 4. Distribution of electricity requirements during the cultivation stage for the evaluated pilot reactor configurations and operating conditions (100\% corresponds to the electricity consumption in S3 per FU listed in

Table 2).

Figure 4 shows that temperature regulation is the main consumer of electricity during cultivation in all evaluated scenarios, with total requirements ranging between $60 \%$ and $90 \%$. The relative contributions of heating and cooling for the tubular systems depend to a large extent on the season. While cooling requires about $55 \%$ of the electricity consumption for cultivation in the summer for both tubular PBRs, it takes less than $10 \%$ of the requirements during fall and has no contribution for the winter period. Regardless of the weather conditions, the ORP needs no cooling because it cools by evaporation of water. All systems need additional heating to maintain the temperature above the set point, even in the summer period, though during this period the heating request is almost only during the night. Electricity requirements for heating are moderate for the tubular reactors in summer $(13 \%$ and $22 \%$ respectively for horizontal and vertical systems) but go above $62 \%$ for the ORP. Heating exceeds $50 \%$ of the total requirements for all the systems operated in fall and winter. 
One of the most significant findings of this work is the high influence of temperature regulation system on the global environmental performance of microalgal cultivation. To the best of our knowledge, no previous LCA study discussed this key issue. Most studies exclude this activity from the system boundaries. In some cases, this seems a realistic assumption, since the operating conditions to estimate the inventory data are based on locations with warm temperatures and sunlight intensities [1, 33], but for these locations the contribution of cooling will increase severely. Indeed, non-cooled closed reactors can reach temperatures above $60^{\circ} \mathrm{C}$ [36], which would make Nannochloropsis cultivation unfeasible, according to its temperature growth range [29]. For other studies that consider less favorable locations $[5,15]$, the effect of temperature regulation is expected to be relevant for the total impacts. Among the published LCA studies, only Taelman et al. [20] was found to specify the use of waste heat to maintain temperature in winter. However, no contribution to the environmental burdens is reported for this input, being treated as a re-used waste flow, and thus having zero impact. The applicability of Taelman's approach is restricted to scenarios in which a sufficient source of waste heat is available. Estimating the total energy needs for temperature regulation is essential to verify for each possible location whether this balance is met or not, and hence, guarantee the sustainability of a large-scale facility. Thus, this estimation may affect the decision-making process depending on the availability of natural cooling or waste heating sources. The quantification provided in the present paper highlights, for the first time, the importance of taking temperature regulation into account when conducting an LCA of a microalgal cultivation system.

When comparing both tubular systems, the electricity consumption for the heating in the vertical system is between 1.3 and 1.9 times higher than for the horizontal PBR. This is caused by the approximately two times larger tube area of the vertical system compared to the horizontal system, which involves a higher heating requirement to keep the temperature at the minimum set temperature of $20^{\circ} \mathrm{C}$. In addition, during daytime, less light is absorbed per loop in the vertical system due to its design, light dilution effect and shading of the tubes. In fall/winter this effect is even more pronounced, because the lower tubes in the loops almost receive less light due to low inclination of the sun and shading.

Aeration and $\mathrm{CO}_{2}$ addition has a relevant contribution to the impact of cultivation (associated with the blower) in the horizontal system (around $20 \%$ in the three scenarios), but is below $10 \%$ for all vertical PBR and ORP scenarios. The high impact of the aeration/ $/ \mathrm{CO}_{2}$ is due to the back pressure of the stripper on pilotscale. Small electrical blowers are not designed to overcome this pressure and for that an oversized blower was needed; on large scale, an air compressor would be used and electricity consumption would decrease largely. The impact of mixing (pumping and paddle wheel) is higher 
for the vertical PBR and ORP contributions than for the horizontal PBR due to higher volumes that needed to be mixed. For the ORP, the electricity consumption of the paddle wheel has already been pointed out as a relevant contributor by other authors $[1,15]$. Although the impact of the paddle wheel in fall is seven times higher than in summer (due to lower productivities), the relative contribution with respect to the total energy requirements is significantly higher for summer due to the lower consumption of other components (e.g. the heating system). The base energy used for monitoring had a minor contribution between $1 \%$ and $7 \%$. In a hypothetical large-scale plant, this contribution may be even lower since such installation would have less equipment and fewer sensors (which are numerous in the case of a pilot plant to allow measuring a higher number of parameters).

\subsection{Comparative environmental assessment of cultivation scenarios}

The comparative evaluation of scenarios is represented in Figure 5, which reflects the environmental profiles, with the ORP operation under fall conditions as a reference.

For the operation in fall and winter, the difference between configurations is decisive. While the environmental burdens of the horizontal PBR operated in fall approximately double compared to the summer period, the effects nearly triple for the vertical tubular system.
For the operation in fall, the horizontal PBR presents between $15 \%$ and $30 \%$ lower impacts than the vertical configuration; mainly due to a $30 \%$ lower electricity consumption for cultivation. The difference between the summer and fall scenarios is much more pronounced in the case of ORP, for which the impacts in fall are between 12 and 17 times higher than for the summer operation. Hence, the fall performance of the ORP is $90 \%$ worse than any of the tubular systems under the same conditions and even exceeds the environmental profile of both PBRs operated in winter (with significantly colder conditions and less irradiation) with $40 \%$.

Although tubular PBRs were operated under winter conditions and present a better behavior than ORP in fall, the environmental burdens are significantly higher, compared to the relatively efficient performance during summer and fall periods. The contributions of the horizontal PBR during winter are about 5 times higher than those of fall, and up to 10 times above those of summer. Similarly, the vertical PBR in winter conditions has an average of 4 times the impacts of fall and more than 12 times the impacts of summer. The environmental impact of the horizontal PBR in fall is between $5-10 \%$ lower than that of the vertical PBR. 
a) CML methodology

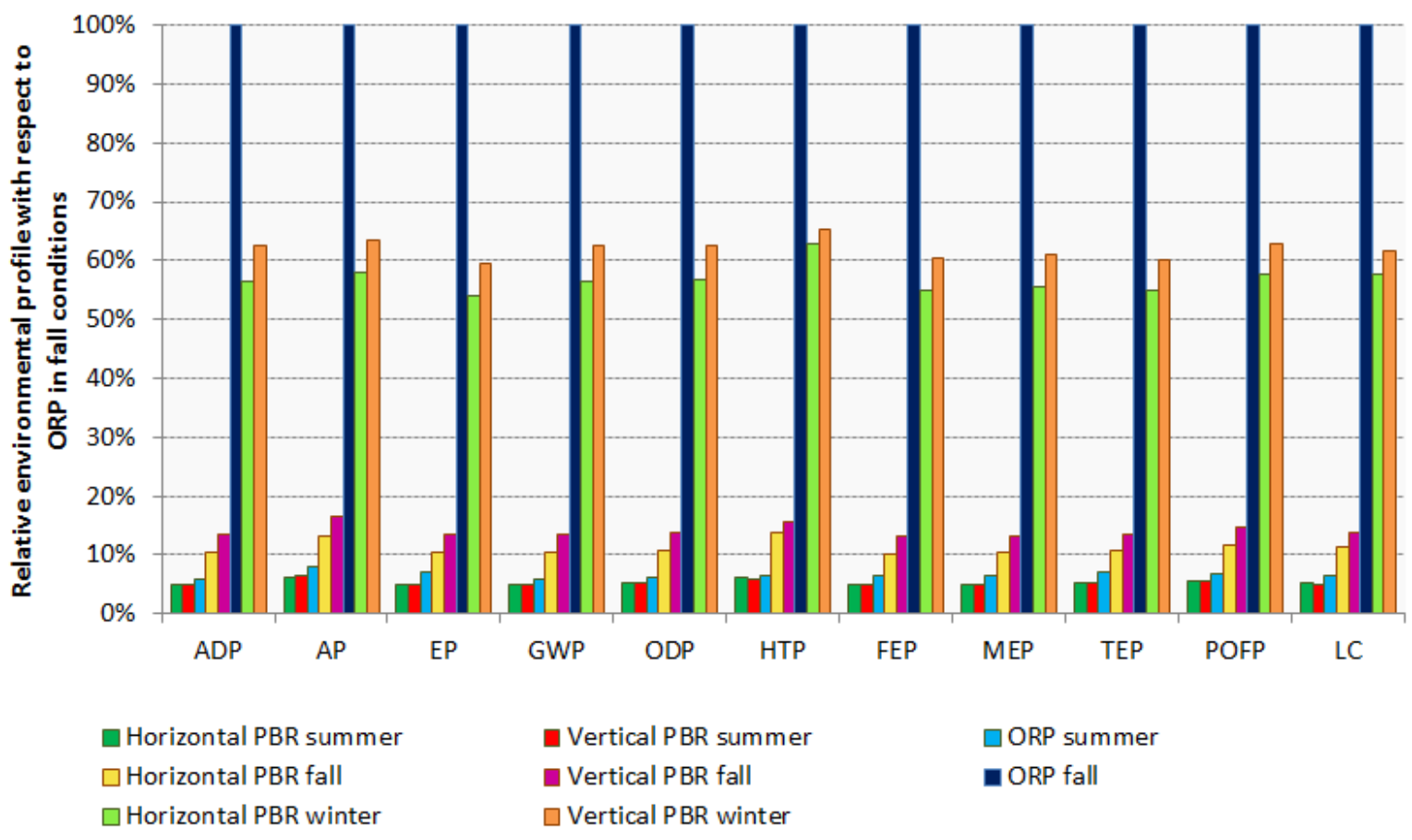

b) CED methodology

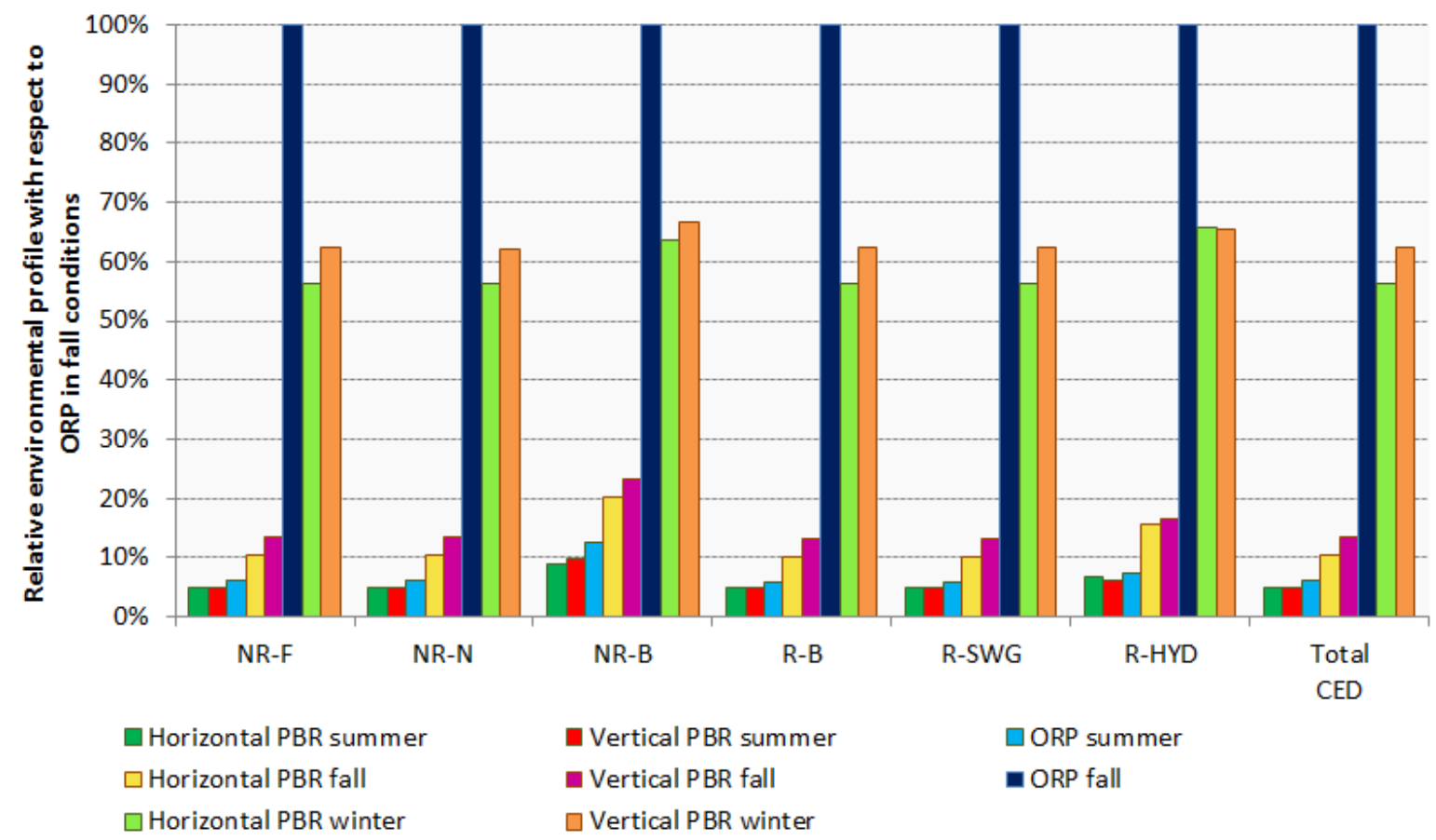

Figure 5. Relative environmental profile of the compared pilot reactor configurations with respect to $\underline{\mathbf{O R P} \text { in fall }}$ conditions for $\mathrm{FU}=1 \mathrm{~kg}$ DW microalgal biomass, according to the impact categories of a) CML methodology and b) CED methodology. 
The results show clearly that the efficient environmental performance of an ORP system is extremely restricted to the environmental conditions, whereas tubular PBRs are less dependent on weather conditions and can maintain a relatively efficient performance for longer periods. The ORP may only be feasible during a limited period of the year, especially for locations with low sunlight intensities, high rainfall and moderate to low temperatures. This is due to the combination of higher electricity consumptions during cultivation stage for heating and a low volumetric productivity for the ORP. This finding is in agreement with the experimental difficulties that prevented the operation of ORP in winter and supports the unfeasibility of ponds for locations with unfavorable thermal and solar conditions.

This outcome differs from the conclusions of previous LCAs, where it was suggested that ORPs have lower environmental impacts than tubular systems due to a more simple operational strategy $[1,15,17]$. The temperature regulation system and the variations in productivity during the seasons are the key factors for this difference, so both factors should be included in environmental assessments. Optimized temperature control strategies (e.g. integration of waste heat, using ground water for cooling or wider temperature ranges) are essential to maintain moderate energy consumption. Moreover, in the aforementioned studies, different algae productivities are used in the inventory analysis stage, due to more favorable locations for the considered facilities. In addition, the use of assumed values may involve data inaccuracies and unrealistic assumptions, which are overcome in this work-thanks to the use of experimental measurements.

\subsection{Scalability of the results}

The systems at AlgaePARC pilot facility are pilot-scale reactors built to explore how laboratory results can be translated to industrial scale systems. However, at any pilot scale size, there are limitations with regard to efficiencies of used equipment (circulation pumps, air blowers and especially temperature control), which are ruled out in upscaling. In addition, during the evaluation period the plant was operated to test the effects of different conditions rather than maintaining a stable optimized operation for long periods, which would be the case in an industrial scale facility. This situation influences significantly the absolute values measured at pilot scale. For example, Taelman et al. [20], indicated that in large scale installations pumps with an efficiency of $80 \%$ are installed, instead of the $11 \%$ efficiency pump in this pilot-plant study.

As mentioned before, culture temperature was controlled by a central electrical chiller and electrical heater. The choice of an electrical cooling/heating was motivated by the easy installation and the flexibility in use for a pilot plant meant for research. However, due to the high primary energy demand the electrical heaters should not be used at industrial scale plants. For large scale applications the use of ground water for cooling and waste heat from a biorefinery or power generation plant are much more 
convenient. If these heat sources are not available, steam generation by direct burning of fuels instead of electrical heating will reduce the impact of heating with a factor 2-2.5 (taking into account that the generation of electricity from primary energy has an efficiency of $35-45 \%$, while steam generation has an efficiency between 80-90\%). Therefore, the values for heating and cooling reported here are much higher than what is expected at large scale, yet still give a good indication on comparison between systems. Further improvements on the environmental impact can be obtained by either moving the production facility to a warmer and sunnier climate [20,38], by using a waste heat stream from e.g. power generation [19] or by choosing a microalgal species that can grow at a wider range of temperatures, and therefore decreasing the need for heating or cooling. Other possibilities would be to adjust the day-night cycles (i.e. using a different set point or even avoid temperature control at night) or to use a buffer tank below the ground to store water during the night after heating it during the day. In addition, heating could be turned off during the night (keeping only frost protection) to further reduce the energy impacts. However, just before sunrise the culture temperature should be above $20^{\circ} \mathrm{C}$ to prevent low productivities.

As the inefficiencies of electrical equipment (e.g. the circulation pumps for the tubular systems) and the temperature regulation at AlgaePARC pilot facilities are analogous for all systems, comparison between systems is still valid. Consequently, these data should not be used to calculate absolute impacts for microalgae cultivation at industrial scale, but they serve well for analysis and comparison of the environmental performance of various process designs and to help debottlenecking these configurations.

Since the energy consumption linked to the temperature control system has been identified as the main contributor to the environmental impacts of the current pilot reactors, we propose the comparison of a set of hypothetical pilot and large-scale scenarios. The hypothetical pilot scenarios are based on the expected reductions on energy consumption when temperature regulation system can be omitted. In this case, the same production conditions are assumed but energy requirements during cultivation are considered to be only necessary for mixing, aeration and monitoring. Operating conditions close to these scenarios might be achieved by selecting a suitable location with favorable weather conditions maintained over long periods of the year, as well as including approaches to improve the efficiency of the systems such as using waste heat or ground buffer deposits. According to the energy consumptions listed in Table $\mathbf{2}$, total electricity consumption in the hypothetical pilot scenarios would range between 88 and $830 \mathrm{MJ}$. Three large-scale scenarios are also proposed, based on the ratio between pilot and full-scale energy consumptions in the cultivation stage reported by Liu et al. [37], which would involve electricity requirements between 26 and 249 $\mathrm{MJ} / \mathrm{FU}$. 
Figure 6 shows a comparison of the best corresponding to summer operation. performing real and hypothetical scenarios

\section{a) CML methodology}

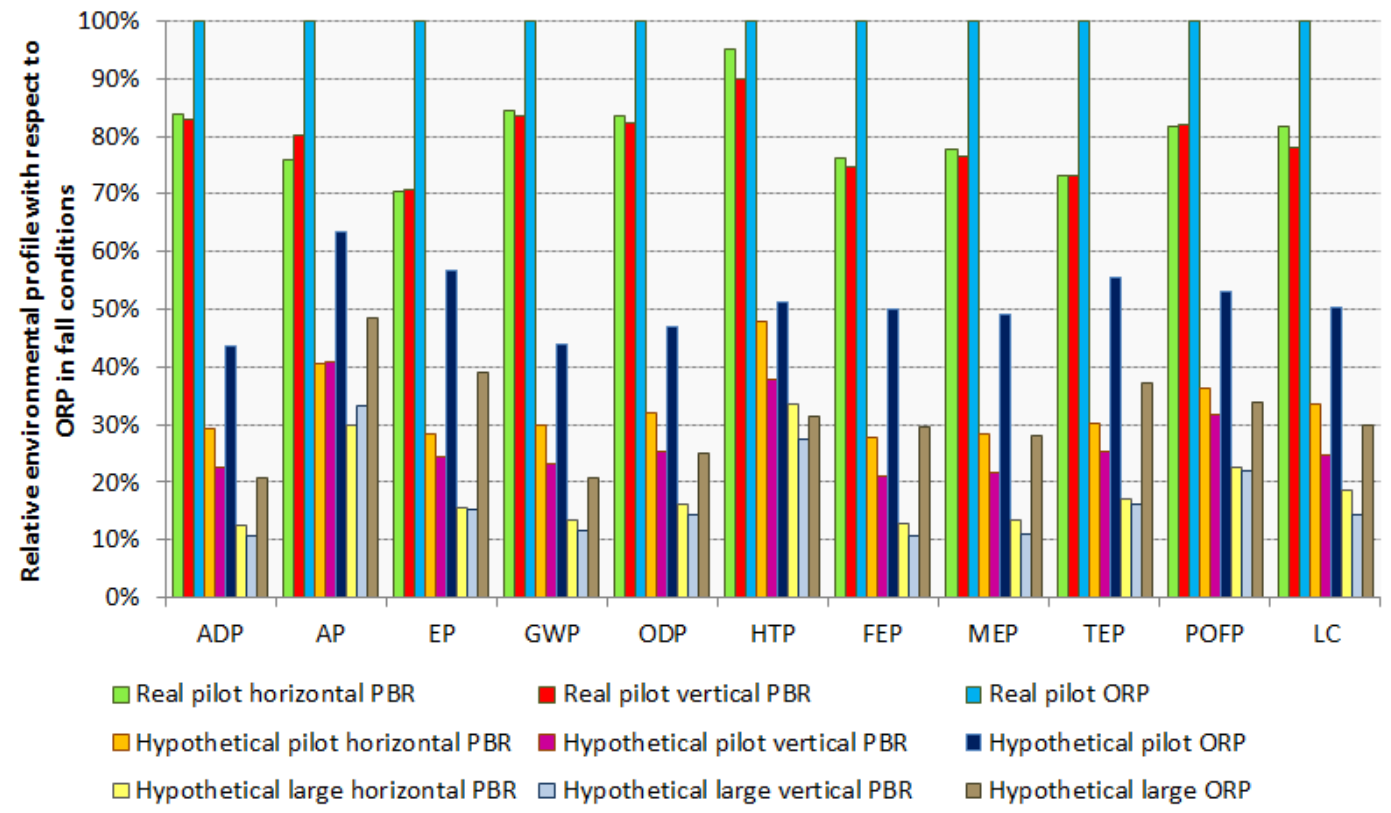

b) CED methodology

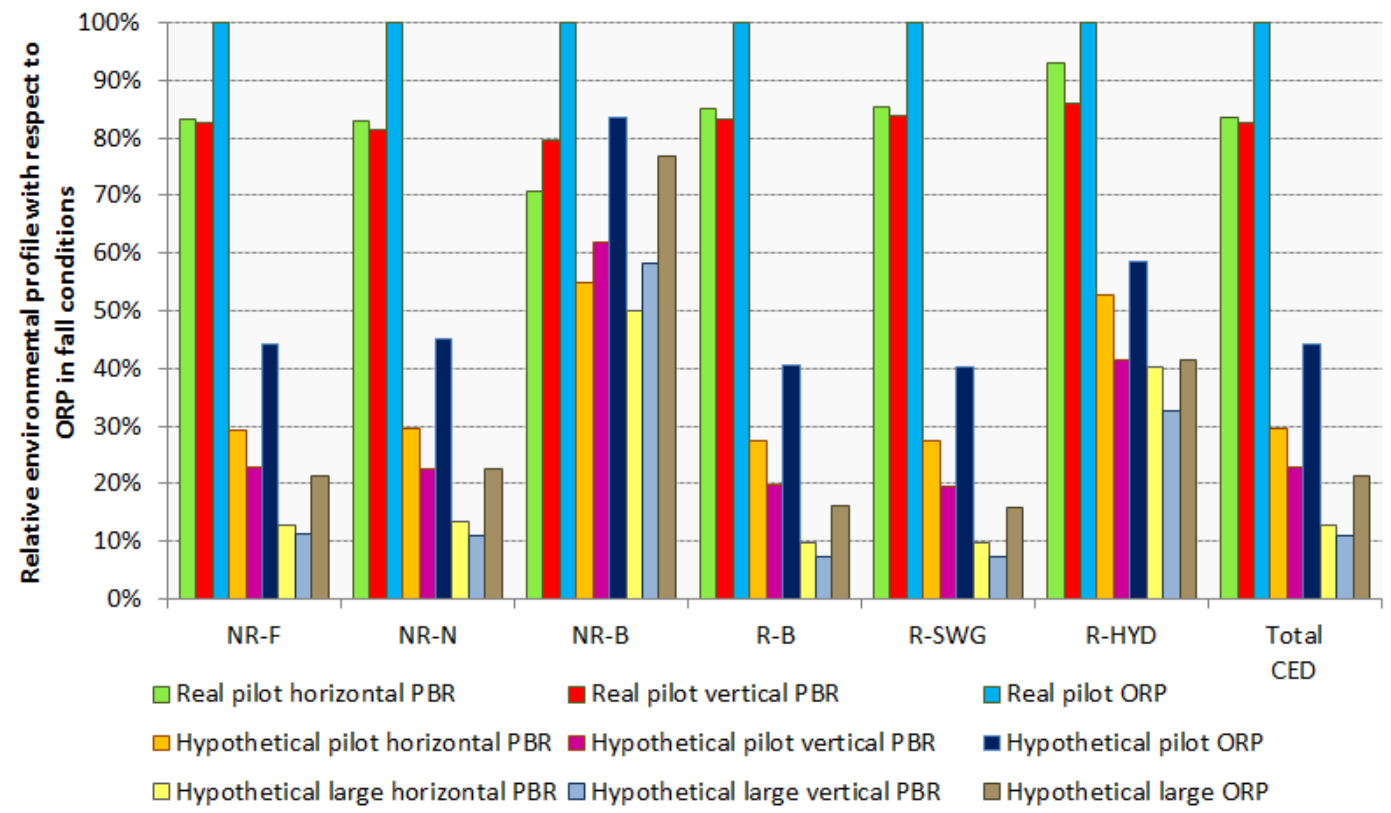

Figure 6. Relative environmental profile of hypothetical pilot and large-scale reactors with respect to pilot ORP in summer conditions for FU=1 kg DW microalgal biomass, according to the impact categories of a) $\mathrm{CML}$ methodology and b) CED methodology. 
According to Figure 6, an optimized pilotscale system without temperature regulation under favorable (summer) conditions could present impact reductions ranging from $17 \%$ (for ORP in NR-B) up to $80 \%$ (for vertical PBR in the categories R-B and R-SWG) with respect to the pilot summer scenario with the highest impact (that is, the ORP operated in summer). When upscaling, total impact reductions are expected to range from $23 \%$ up to $90 \%$. When comparing hypothetical to real equivalent system, an optimized pilot horizontal PBR could have environmental improvements between $23 \%$ and $68 \%$ with respect to AlgaePARC system, while the large-scale reactor would allow environmental impact reductions between $50 \%$ and $90 \%$. The reductions for an optimized pilot-scale vertical system would range between $22 \%$ and $77 \%$ and for an ORP, between $17 \%$ and $60 \%$. In the case of large-scale vertical PBR, we could expect total environmental improvements from $42 \%$ and $93 \%$, whereas the ORP would improve between $23 \%$ and $84 \%$. If we consider the comparison of these optimized systems to the worst pilot scenario (ORP operated in fall), impact reductions between $90 \%$ and $99 \%$ could be achieved. Despite the difference of hypothetical large-scale systems with respect to real pilot reactors a common trend has been found: The hypothetical ORP reactor has higher environmental impacts than the corresponding horizontal and vertical PBR under all the evaluated operation conditions. This means that the complexity of tubular systems in terms of energy-consuming elements is compensated by the larger volumetric productivity. The results presented in this section suggest that the upscaling and optimization of microalgal reactors can involve significant environmental improvements, even though the hypothetical large-scale scenarios were modeled according to a set of assumptions. The applicability of the results relies on the possibility to maintain the same biomass productivities as those obtained with the temperature control system.

The findings of this paper related to the dependency of the environmental performance on the weather conditions may contribute to the role of LCA as a tool for process design and optimization towards large-scale systems. The high influence of the weather conditions should be taken into account for the selection of appropriate reactor configurations depending on the geographic location. High productivities with reduced heat requirements can be achieved in a relatively easy manner by placing the facility in a suitable location with warm temperatures and high solar irradiations. Thus, an open pond could be suitable for a location with warm temperatures and low rainfall, whereas a closed system would be more efficient from an environmental point of view in the case of locations with more moderate temperatures or high fluctuations. However, locations with too high temperatures should also be avoided for closed systems to reduce or eliminate cooling needs. The availability of natural sources or waste streams that can be used for temperature regulation is also an essential 
factor to take into account when selecting the location.

\section{Conclusions}

LCA is a powerful tool to quantify the environmental performance of microalgae cultivation. A comparative LCA based on real plant data for outdoor pilot raceway pond, horizontal and vertical tubular photobioreactors at AlgaePARC (The Netherlands) identified temperature control as the main cause of impact for all systems, regardless of the cultivation season. ORP showed higher environmental impacts than both tubular PBRs, as the latter compensate energy-consuming elements with higher productivity.

The results of this paper highlight the relevance of LCA as a tool for process design and optimization. In the case of microalgal cultivation, weather conditions and availability of sources for temperature regulation have been identified as essential factors to take into account when selecting a geographic location. For a given location, this work can contribute to identify an appropriate reactor configuration according to environmental and energetic criteria. Moreover, the simulations of hypothetical optimized scenarios at pilot and large scale provide information on the potential environmental improvements. Despite some differences influencing the scalability of the results, the use of experimental data from outdoor pilot systems instead of limiting to process simulations from lab-scale data is essential to analyze and debottleneck the environmental impact towards large-scale cultivation.

\section{Acknowledgements}

The work presented in this paper has been developed within the framework of the BAMMBO Project (Project reference: FP7 KBBE-2010-4). The authors P. Pérez-López, G. Feijoo and M.T. Moreira belong to the Galician Competitive Research Group GRC 2013-032. P. Pérez-López would like to express her gratitude to the Spanish Ministry of Education for awarding a research scholarship (AP2012-1605). Furthermore, the authors would like to thank the Ministry of Economic Affairs, Agriculture and Innovation and Province of Gelderland, and BioSolar Cells, BASF, BioOils, Drie Wilgen Development, DSM, Exxon Mobil, GEA Westfalia Separator, Heliae, Neste Oil, Nijhuis, Paques, Cellulac, Proviron, Roquette, SABIC, Simris Alg, Staatsolie Suriname, Synthetic Genomics, TOTAL and Unilever for the financial support of the AlgaePARC research program.

\section{References}

[1] Draaisma RB, Wijffels RH, Slegers PM, Brentner LB, Roy A, Barbosa MJ. Food commodities from microalgae. Curr Opin Biotechnol 2013; 24(2):169-177.

[2] Hallenbeck PC, Grogger M, Mraz M, Veverka D. Solar biofuels production with microalgae. Appl Energy 2016; 179, 136-145. 
[3] Lam MK, Lee KT. Microalgae biofuels: A critical review of issues, problems and the way forward. Biotechnol Adv 2012; 30(3):673-690.

[4] Nienhueser IA, Qiu Y. Economic and environmental impacts of providing renewable energy for electric vehicle charging - A choice experiment study. Appl Energy 2016; 180:256-268.

[5] Clarens AF, Resurreccion, EP, White MA, Colosi LM. Environmental life cycle comparison of algae to other bioenergy feedstocks. Environ Sci Technol 2010; 44(5):1813-1819.

[6] Zhang H, Xu W, Zhou D, Cao J. Waste cooking oil-to-energy under incomplete information: Identifying policy options through an evolutionary game. Appl Energy 2017; 185(1):547-555.

[7] Pérez-López P, González-García S, Jeffryes C, Agathos SN, McHugh E, Walsh D, Murray P, Moane S, Feijoo G, Moreira MT. Life cycle assessment of the production of the red antioxidant carotenoid astaxanthin by microalgae: from lab to pilot scale. J Clean Prod 2014; 64:332-344.

[8] Van Boxtel AJB, Pérez-López P, Breitmayer E, Slegers PM. The potential of optimized process design to advance LCA performance of algae production systems. Appl Energy 2015; 1122-1127.

[9] Brentner LB, Eckelman MJ, Zimmerman JB. Combinatorial life cycle assessment to inform process design of industrial production of algal biodiesel. Environ Sci Technol 2011; 45(16):7060-7067.

[10] Chisti Y, Yan J. Energy from algae: Current status and future trends: Algal biofuels - A status report. Appl Energy 2011; 88(10):32773279.

[11] Fortier MOP, Roberts GW, Stagg-Williams SM, Sturm B.S.M.. Life cycle assessment of bio-jet fuel from hydrothermal liquefaction of microalgae. Appl Energy 2014; 122: 73-82.

[12] Woertz IC, Benemann JR, Du N, Unnasch S, Mendola D, Mitchell BG, Lundquist TJ. Life cycle GHG emissions from microalgal biodiesel - A CA-GREET model. Environ Sci Technol 2014; 48(11):6060-6068.

[13] Razon LF, Tan R. Net energy analysis of the production of biodiesel and biogas from the microalgae: Haematococcus pluvialis and Nannochloropsis. Appl Energy 2011; 88:35073514.

[14] Chiaramonti D, Maniatis K, Tredici MR, Verdelho V, Yan J. Life Cycle Assessment of algal biofuels: Needs and challenges. Appl Energy 2015; 154:1049-151.

[15] Stephenson AL, Kazamia E, Dennis JS, Howe CJ, Scott SA, Smith AG. Life-cycle assessment of potential algal biodiesel production in the United Kingdom: A comparison of raceways and air-lift tubular bioreactors. Energy Fuels 2010; 24:40624077.

[16] Sills DL, Paramita V, Franke MJ, Johnson MC, Akabas TM, Greene CH, Tester JW. Quantitative uncertainty analysis of Life Cycle 
Assessment for algal biofuel production.

Environ Sci Technol 2013; 47:687-694.

[17] Jorquera O, Kiperstok A, Sales EA, Embiruçu

M, Ghirardi ML. Comparative energy lifecycle analyses of microalgal biomass production in open ponds and photobioreactors. Bioresour Technol 2010; 101(4):1406-1413.

[18] Bosma R, de Vree JH, Slegers PM, Janssen M, Wijffels RH, Barbosa MJ. Design and construction of the microalgal pilot facility AlgaePARC. Algal Res 2014; 6:160-169.

[19] Slade R, Bauen A. Micro-algae cultivation for biofuels: Cost, energy balance, environmental impacts and future prospects. Biomass Bioenerg 2013; 53:29-38.

[20] Taelman SE, De Meester S, Roef L, Michiels M, Dewulf J. The environmental sustainability of microalgae as feed for aquaculture: A life cycle perspective. Bioresour Technol 2013; 150:513-522.

[21] Moody JW, McGinty CM, Quinn JC. Global evaluation of biofuels potential from microalgae. PNAS 2014; 111(23):8691-8696.

[22] Slegers PM, van Beveren PJM, Wijffels RH, van Straten G, van Boxtel AJB. Scenario analysis of large scale algae production in tubular photobioreactors. Appl Energy 2013; 105:395-406.

[23] Collet P, Lardon L, Hélias A, Bricout S, Lombaert-Valot I, Perrier B, Lépine O, Steyer JP, Bernard O. Biodiesel from microalgae Life cycle assessment and recommendations for potential improvements. Renew Energy 2014; 71:525-533.

[24] Montazeri M, Soh L, Pérez-López P, Zimmerman JB, Eckelman MJ. Timedependent life cycle assessment of microalgal biorefinery co-products. Biofuels Bioprod Bioref 2016; 10(4):409-421.

[25] Rodolfi L, Chini Zitelli G, Bassi N, Padovani G, Biondi N, Bonini G, Tredici MR. Microalgae for oil: Strain selection, induction of lipid synthesis and outdoor mass cultivation in a low-cost photobioreactor. Biotechnol Bioeng 2009; 102(1):100-112.

[26] De Vree JH, Bosma R, Janssen M, Barbosa MJ, Wijffels RH. Comparison of four outdoor pilot-scale photobioreactors. Biotechnol Biofuels 2015; 8:215.

[27] ISO 14040. Environmental Management Life Cycle Assessment - Principles and Framework, Geneva, Switzerland, 2006.

[28] Azapagic A, Clift R. Allocation of environmental burdens in multiple-function systems. J Clean Prod 1999; 7(2):101-119.

[29] Sandnes JM, Källqvist T, Wenner D, Gislerød HR, 2005. Combined influence of light and temperature on growth rates of Nannochloropsis oceanica, linking cellular responses to large-scale biomass production. J Appl Phycol 2005; 17:515-525.

[30] Frischknecht R, Jungbluth N, Althaus HJ, Doka G, Heck T, Hellweg S, Hischier R, Nemecek T, Rebitzer G, Spielmann M, Wernet G. Overview and methodology. Ecoinvent 
report No. 1. v2.0. Swiss Centre for Life Cycle

Inventories, Dübendorf; 2007a.

[31] Guinée JB, Gorrée M, Heijungs R, Huppes G,

Kleijn R, de Koning A, van Oers L, Wegener

Sleeswijk A, Suh S, Udo de Haes HA, de

Bruijn $H$, van Duin R, Huijbregts MAJ.

Handbook on life cycle assessment:

Operational guide to the ISO standards.

Dordrecht (The Netherlands): Kluwer

Academic Publishers; 2002.

[32] Frischknecht R, Jungbluth N, Althaus HJ,

Bauer C, Doka G, Dones R, Hischier R,

Hellweg S, Humbert S, Köllner T, Loerinick

Y, Margni M, Nemecek T. Implementation of

Life Cycle Impact Assessment methods.

Ecoinvent report No. 3. v2.0. Swiss Centre for

Life Cycle Inventories, Dübendorf; 2007b.

[33] Collet P, Hélias A, Lardon L, Steyer JP,

Bernard O. Recommendations for Life Cycle Assessment of algal fuels. Appl Energy 2015; 154:1089-1102.

[34] Lardon L, Hélias A, Sialve B, Steyer JP, Bernard, O. Life-cycle assessment of biodiesel production from microalgae. Environ Sci Technol 2009; 43(17):6475-6481.

[35] Goedkoop M, Oele M, Leijting J, Ponsioen T, Meijer E. Introduction to LCA with SimaPro. Pré-Consultants 2013.

[36] Ruiz J, Olivieri G, de Vree J, Bosma R, Willems P, Reith JH, Eppink MHM, Kleinegris DMM, Wijffels RH, Barbosa MJ. Towards industrial products from microalgae. Energy Environ Sci 2016; 9, 3036-3043.
[37] Liu X, Saydah B, Eranki P, Colosi LM, Greg Mitchell B, Rhodes J, Clarens AF. Pilot-scale data provide enhanced estimates of the life cycle energy and emissions profile of algae biofuels produced via hydrothermal liquefaction. Bioresour Technol 2013; 148:163-171.

[38] Norsker NH, Barbosa MJ, Vermuë $\mathrm{MH}$, Wijffels RH. Microalgal production - a close look at the economics. Biotechnol Adv 29(1):24-27. 